Discussion Paper No. 17-037

\title{
Minority Share Acquisitions and \\ Collusion: Evidence from the Introduction of National Leniency Programs
}

Sven Heim, Kai Hüschelrath, Ulrich Laitenberger, and Yossi Spiegel

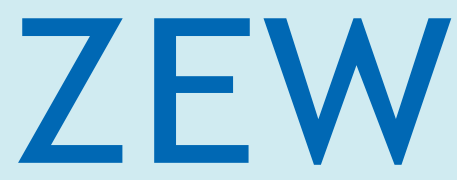

Zentrum für Europäische Wirtschaftsforschung $\mathrm{GmbH}$

Centre for European

Economic Research 
Discussion Paper No. 17-037

\title{
Minority Share Acquisitions and Collusion: Evidence from the Introduction of National Leniency Programs
}

\author{
Sven Heim, Kai Hüschelrath, \\ Ulrich Laitenberger, and Yossi Spiegel
}

Download this ZEW Discussion Paper from our ftp server:

http://ftp.zew.de/pub/zew-docs/dp/dp17037.pdf

Die Discussion Papers dienen einer möglichst schnellen Verbreitung von neueren Forschungsarbeiten des ZEW. Die Beiträge liegen in alleiniger Verantwortung der Autoren und stellen nicht notwendigerweise die Meinung des ZEW dar.

Discussion Papers are intended to make results of ZEW research promptly available to other economists in order to encourage discussion and suggestions for revisions. The authors are solely responsible for the contents which do not necessarily represent the opinion of the ZEW. 


\title{
Minority Share Acquisitions and Collusion: Evidence from the Introduction of National Leniency Programs*
}

\author{
Sven Heim†, Kai Hüschelrath $\ddagger$ Ulrich Laitenberger
}

September 30, 2017

\begin{abstract}
There is a growing concern that minority shareholding (MS) in rival firms may facilitate collusion. To examine this concern, we exploit the fact that leniency programs (LPs) are generally recognized as a shock that destabilizes collusive agreements and study the effect that the introduction of an LP has on horizontal MS acquisitions. Using data from 63 countries over the period 1990-2013, we find a large increase in horizontal MS acquisitions in the year in which an LP is introduced, especially in large rivals. The effect is present however only in countries with an effective antitrust enforcement and low levels of corruption and only when the acquisitions involve stakes of $10 \%-20 \%$. These results suggest that MS acquisitions may stabilize collusive agreements that were destabilized by the introduction of the LP.
\end{abstract}

Keywords: minority shareholdings, collusion, leniency programs, cartel stability

JEL Class: G34, K21, L41

\footnotetext{
${ }^{*}$ We thank Bastian Sattelberger for excellent research assistance. In addition we thank Dirk Czarnitzki, Christoph Engel, Joseph Hilbe, Francois Laisney, Axel Ockenfels, Sascha Steffen, Rune Stenbacka, Achim Wambach, Christine Zulehner and participants at the $2017 \mathrm{MaCCI}$ conference and the 2017 EARIE conference for helpful comments and suggestions.

${ }^{\dagger}$ ZEW Centre for European Economic Research and MaCCI Mannheim Centre for Competition and Innovation, L7,1, D-68161 Mannheim, Germany; E-Mail: heim@zew.de.

$\ddagger$ ZEW Centre for European Economic Research, MaCCI Mannheim Centre for Competition and Innovation and University of Mannheim, L7,1, D-68161 Mannheim, Germany; E-Mail: hueschelrath@zew.de.

$\S$ Telecom ParisTech, Departement Sciences economiques et sociales, 46 Rue Barrault, 75013 Paris, France, and ZEW as above; E-Mail: laitenberger@enst.fr.

${ }^{\top}$ Coller School of Management, Tel Aviv University, Ramat Aviv, Tel Aviv 69978, Israel, CEPR and ZEW as above; E-Mail: spiegel@post.tau.ac.il.
} 


\section{Introduction}

There is a growing concern in recent years about the potential anticompetitive effects of partial cross ownership among rival firms, that is, cases in which firms acquire minority stakes (MS) in actual or potential rivals. ${ }^{1}$ For instance, a 2014 European commission white paper argues that "The Commission's experience, the experiences of Member States and third countries, but also economic research show that in some instances the acquisition of a noncontrolling minority stake, such as one firm acquiring a $25 \%$ stake in a competitor, can harm competition and consumers" (European Commission, 2014). A similar concern was voiced by the OECD in a 2008 policy roundtable: "Minority shareholdings and interlocking directorates can have negative effects on competition, either by reducing the minority shareholder's incentives to compete (unilateral effects), or by facilitating collusion (coordinated effects)" (OECD, 2008).

Despite this growing concern, merger regulations do not apply in many jurisdictions when the acquisition does not give the acquirer control over the target firm, and in fact, the competition authority is not even aware of the acquisitions in many cases. ${ }^{2}$ But even when merger regulations apply, MS acquisitions, especially those deemed to be "passive," are either granted a de facto exemption from antitrust liability or have gone unchallenged by the competition authority (Gilo, 2000). ${ }^{3}$ For example, Nain and Wang (2016) find that in the U.S., where the Federal Trade Commission and the Department of Justice have the competence to review MS acquisitions, less than $1 \%$ of all MS transactions are challenged, and even fewer are blocked.

The Industrial Organization literature has shown that MS acquisitions may raise competitive concerns due to unilateral and coordinated effects. ${ }^{4}$ Reynolds and Snapp (1986), Bresnahan and Salop (1986), Farrell and Shapiro (1990), and Shelegia and Spiegel (2012) show that following an MS acquisition in a rival, the acquirer softens its competitive behavior, because it internalizes some of the competitive externality it imposes on the rival. ${ }^{5}$ The anticompetitive effects of MS acquisitions could be even larger if the acquisition gives the acquirer some degree of control over the target firm, because then the acquirer can also soften the target's behavior in addition to its own behavior. In fact, Salop and O'Brien (2000) argue that MS acquisitions could lead to even less competitive outcomes than full horizontal mergers if the acquirer's control rights substantially exceed its cash

\footnotetext{
${ }^{1}$ There is also a growing concern about common ownership: cases where the same set of shareholders own several competing firms. Recent papers by Azar, Schmalz, and Tecu (2016), and Azar, Raina, and Schmalz (2016) show that airline ticket prices and bank fees are significantly higher when competing firms are held by the same institutional investors, such as Berkshire Hathaway, BlackRock, and Vanguard. Panayides and Thomas (2017) study data from 119 U.S. industries over the period 1997-2014 and find that common ownership by institutional investors (blockholders) is associated with higher industry profitability, due to reduced expenditures.

${ }^{2}$ In some countries including Austria, Canada, Germany, Japan, the U.S., and the UK, competition authorities have the competence to review MS acquisitions that raise competition concerns. See European Commission (2014). For a comprehensive review of antitrust policies concerning MS acquisitions, see Fotis and Zevgolis (2016).

${ }^{3}$ Gilo (2000) argues that the lenient approach towards passive investments in rivals in the U.S. stems from the courts' interpretation of the exemption for stock acquisitions "solely for investment" included in Section 7 of the Clayton Act.

${ }^{4}$ See European Commission (2013) and O'Brien and Waehrer (2017) for recent literature surveys.

${ }^{5}$ Interestingly, Farrell and Shapiro (1990) show that in the context of a Cournot model, the acquirer's softer behavior induces rivals to expand their output; if rivals are more efficient than the acquirer, the output shift can actually enhance welfare. Brito, Cabral and Vasconcelos (2014) study the welfare effects of different forms of a divestiture of a firm's partial ownership in a rival.
} 
flow rights. ${ }^{6}$

Malueg (1992), Dietzenbacher, Smid, and Volkerink (2000), and Gilo, Moshe, and Spiegel (2006) show that MS acquisitions can also facilitate tacit collusion. The reason is that when firms hold MS in rivals, they internalize part of the negative competitive externality that they impose on rivals when they deviate from a collusive agreement. Although MS may also soften competition once a collusive agreement breaks down and hence weaken the incentive to collude, the first effect typically dominates, so firms have a stronger incentive to collude. ${ }^{7,8}$

Despite the increasing concern about the competitive effects of MS acquisitions, empirical evidence on these effects is still scarce. Dietzenbacher, Smid, and Volkerink (2000) use cross ownership data from the Dutch financial sector to calibrate oligopoly models with constant marginal costs. They conclude that the price-cost margins in the Dutch financial sector are $8 \%$ higher in a Cournot model and $2 \%$ higher in a differentiated goods, price competition, model than they would be absent cross-ownership. Brito, Ribeiro, and Vasconcelos (2014) propose a methodology to evaluate the unilateral effects of partial cross ownership and apply it to several MS acquisitions in the wet shaving industry. Among other things, they estimate that Gillette's acquisition of a $22.9 \%$ nonvoting equity interest in Wilkinson Sword in 1990 had only a negligible negative effect on prices, but a counterfactual acquisition of a $22.9 \%$ voting equity would have led to a $2.1 \%-2.7 \%$ increase in the price of Wilkinson Sword wet shaving razor blades. Nain and Wang (2016) find in a study of 774 horizontal MS acquisitions in U.S. manufacturing industries announced in 1980-2010 that the acquisitions raised prices by $2 \%$ and raised price-cost margins by $0.7 \%$, even after controlling for other factors that may have affected prices and price cost margins.

In this paper, we wish to shed light on the competitive effects of MS acquisitions and in particular, examine whether they facilitate collusion. As far as we know, there is still no empirical evidence on the effects of MS acquisitions on the ability of firms to collude (tacitly or explicitly). Our empirical strategy relies on the fact that it is generally accepted that leniency programs (LP), which offer amnesty from government penalties to corporations and individuals who come forward and disclose information about illegal antitrust activity, such as price-fixing, and fully cooperate with subsequent investigations, can destabilize collusive agreements. Indeed, following the U.S. lead in 1993, many countries have introduced an LP precisely in order to detect existing cartels and deter new collusive agreements. ${ }^{9}$ Hence, once an LP is introduced, firms would need to stabilize

\footnotetext{
${ }^{6}$ Intuitively, the acquirer may then have an incentive to use his control rights to soften the target's behavior (by setting high prices or low quantities) in order to boost the profits of his own firm. The resulting outcome could be less competitive than under a full horizontal merger, where the acquirer cares equally about the profits of both firms. Foros, Kind, and Shaffer (2011) show that when the acquirer fully controls the target, a partial ownership stake may be more profitable than full ownership because then the acquirer chooses a softer stragety for the target than under full ownership. If the two firms compete with a rival and strategies are strategic complements, the rival also softens its behavior in a way that may benefit the acquirer.

${ }^{7}$ Malueg (1992) shows in a symmetric Cournot duopoly, in which firms hold the same ownership stakes, $v$, in one another, that the second effect may dominate the first, in which case an increase in $v$ hinders collusion rather than facilitates it. But if this were the case, firms would not wish to increase $v$, so we should not observe such an outcome.

${ }^{8}$ While MS typically soften competition, they may also have a bright side. Lopez and Vives (2016) (general oligopoly model with symmetric cross or common ownership structure) and Shelegia and Spiegel (2016) (Bertrand duopoly with asymmetric cross-ownership structure) show that MS in rivals may encourage cost-reducing investments.

${ }^{9}$ For a review of LPs in different countries, see OECD (2012) and UNCTAD (2010).
} 
their collusive agreements; acquiring MS in rivals is one way of doing it. Accordingly, we examine whether the introduction of an LP encourages MS acquisitions.

To this end, we construct a panel data set that covers 63 countries, of which 54 have introduced a national LP between 1990 and 2013. Applying count data models, we find robust evidence that in the year in which a national LP is introduced in a given country, there is a large and significant increase in the number and volume of horizontal MS acquisitions between firms based in that country. This effect holds, however, only in countries with an effective antitrust enforcement and a low level of corruption. Otherwise, the introduction of an LP has no significant effect on MS acquisitions, presumably because the national LP is not perceived by colluding firms as an effective threat. We also find that the effect is present when investing in large firms and when the acquired stake gives the acquirer a 10\% - 20\% share in the target firm; such stakes are significant in size, but normally do not trigger merger notification. ${ }^{10}$

Following the pioneering paper of Motta and Polo (2003), a large and growing theoretical and experimental literature has emerged which examines the competitive effects of LPs (see Spagnolo and Marvao (2016) for a recent literature review). This literature shows that LPs affect competition in several ways and that in general they hinder collusion. In Harrington (2008), an LP has three distinct effects on collusion: the "Deviator Amnesty" effect hinders collusion because it allows a deviating firm to apply for leniency at the same time it undercuts the collusive price and hence it lowers the cost of cheating. The "Race to the Courthouse" effect destabilizes collusive agreements because each firm is concerned that another cartel member would apply for leniency and hence it is better off doing so first. Finally, the "Cartel Amnesty" effect is a countervailing force since the ability of each firm to apply for leniency in the future, if needed, lowers the cost of joining the cartel in the first place. ${ }^{11}$ Harrington shows that when an LP is optimally designed, the first two effects dominate the third, meaning that LPs hinder collusion. Harrington and Chang (2009) explore the interaction between the three effects of LPs in the context of a dynamic model in which cartels form and collapse on the equilibrium path. They show that the introduction of an LP reduces the longrun frequency of cartels and raises the rate at which they are discovered. Harrington (2013) shows that when each cartel member has private information about the likelihood that the competition authority will be able to convict the cartel without a cooperating firm, an LP can also destabilize the cartel due to a "Preemption" effect, which arises because each firm fears that another firm may believe that the probability of detection is high, and will apply for amnesty. Hence, firms may wish to apply for amnesty to preempt rivals from doing so.

The empirical literature on LPs largely confirms the theoretical prediction that LPs hinder collusion. For instance, Levenstein and Suslow (2011), Abrantes-Metz et al. (2013), De (2010), Zhou (2012, 2016), and Hellwig and Hüschelrath (2017) show that the introduction of an LP has a

\footnotetext{
${ }^{10}$ See OECD (2008): in most countries, an MS acquisition triggers the requirement for a merger notification only when it results in joint control, i.e., the right to block major decisions within the target.

${ }^{11}$ Polo and Motta (2003) also show that an LP might, under some conditions, facilitate collusion because the possibility of reporting and receiving immunity from fines reduces the expected costs of cartel detection and conviction. Likewise, Harrington and Chang (2013) find that an LP can result in more cartels, although they identify situations and policies a competition authority can pursue that make it more likely that an LP will hinder collusion.
} 
significantly negative effect on the duration of detected cartels. ${ }^{12}$ Miller (2009) develops a theoretical model of cartel behavior and uses it to identify the effect of a LP on cartel formation and detection rates. He finds that the number of cartel discoveries increased immediately after a new LP was introduced in the U.S. in August 1993, but then fell below initial levels. The latter is consistent with the notion that LPs deter cartel formation.

The remainder of the paper is organized as follows. In Section 2 we discuss our empirical strategy and in Section 3 we present our data. The estimation results are in Section 4 and in Section 5 we show robustness checks. We conclude in Section 6. The Appendix contains additional tables that are not included in the main text.

\section{Empirical Strategy}

To examine empirically the effects of MS on collusion, we will use the introduction of a national LP in a given country as an exogenous shock, which destabilize collusive agreements between firms located in that country. The idea is that faced with this negative shock, colluding firms may wish to resort to MS acquisition, as a way to stabilize their collusive agreements. While firms may use MS as a collusive device even before an LP is in place, an MS acquisition is typically costly due to various transaction costs, and if the shares are acquired from atomistic shareholders, the acquirer makes no money on the acquired shares. ${ }^{13}$ Consequently, it is reasonable to expect firms to be reluctant to acquire MS in rivals if they have other means to sustain collusion. Since the introduction of an LP destabilizes collusive agreements, it makes firms more willing to acquire MS in rivals, which suggests in turn that the introduction of a national LP would be followed by an increase in MS acquisitions in rival firms. If the intention of firms is only to stabilize existing agreements, the increase in MS acquisitions would be immediate and short-term. If the intention is to facilitate new collusive agreements, we should observe a permanent increase in MS acquisitions following the introduction of an LP.

The idea of using the introduction of an LP as a negative shock to collusive agreements was first used by Sovinsky and Helland (2012). They argue that the 1993 revision of the U.S. LP and its adjustment in 1995 have reduced the gains from collusive relationships in the form of research joint ventures (RJV). They find a significant drop in the probability of joining an RJV after 1993: $34 \%$ among telecommunications firms, 33\% among computer and semiconductor manufacturers, and $27 \%$ among petroleum refining firms. Dong, Massa, and Zaldokas (2016) show that the introduction of LPs in 63 countries between 1990 and 2012 led to more cartel convictions and lower average gross margins of affected firms, and moreover, was followed by an increase of takeovers and mergers with rivals. $^{14}$ In a similar vein, Marx and Zhou (2015) find that the EC's LP, first introduced in 1996,

\footnotetext{
${ }^{12}$ Brenner (2009) is an exception: he does not find evidence that the EU LP destabilized cartels. But as Spagnolo and Marvao (2016) argue, Brenner's analysis refers to the first version of the EU LP, which was poorly designed and was revised in 2002 and 2006. Later empirical studies - that are able to take the first (or even both) revision(s) into account - find clear empirical support for a destabilizing impact of LPs.

${ }^{13}$ This is due to Grossman and Hart's (1980) well-known free-rider problem.

${ }^{14}$ Davies, Ormosi, and Graffenberger (2015) also study the relationship between cartels and mergers, although
} 
had a significant and robust large positive effect on mergers. They also find that the EC's cartel settlement procedure in 2008, which allows late confessors to obtain fine reductions outside the LP, had a significant large negative effect on mergers, presumably because it lowered the cost of collusion and made mergers less attractive compared to collusion. Unlike the last two papers, which examine mergers and acquisitions, we are interested in the effect of LPs on MS acquisitions as an indirect evidence for the proposition that MS facilitate collusion.

To this end, we use a panel of 63 countries over the period 1990-2013, and estimate the following count data model:

$$
M S_{i t}=\exp \left(\boldsymbol{\alpha} \mathbf{L P}_{i t}+\boldsymbol{\beta} \mathbf{X}_{i t}+\xi_{i}+\xi_{t}+\varepsilon_{i t}\right)
$$

where $M S_{i t}$ is a measure of MS acquisitions of rivals in country $i$ in year $t, L P_{i t}$ is a vector of dummies several years before and after year $t$ in which an LP was introduced in country $i, X_{i t}$ is a vector of macroeconomic and financial markets control variables, $\xi_{i}$ is country fixed effect, $\xi_{t}$ is a year fixed effect, and $\varepsilon_{i t}$ is a noise term. In some specifications we replace $L P_{i t}$ by $L P_{i t} \times Y_{i}$, where $Y_{i}$ reflects two country-specific indices that control for the efficacy of antitrust enforcement and the level of corruption in country $i$. We control for these factors because in countries with ineffective antitrust enforcement and/or high levels of corruption, an LP is unlikely to destabilize collusive agreements, and hence may not trigger the need to resort to MS acquisitions. We therefore expect to see more MS acquisitions following the introduction of LPs only in countries with effective antitrust enforcement and/or low levels of corruption.

We include the vector $X_{i t}$ in our estimation to control, at least partially, for various forces that may drive MS acquisitions beside the desire to soften competition. For example, Meadowcroft and Thompson (1986) study UK data and find that about $25 \%$ of all MS are acquired as a first step in a planned takeover or to block a takeover by a third party, $15 \%$ are due to diversification motives into new sectors, and about $30 \%$ are intended to support trading agreements. ${ }^{15}$ Allen and Phillips (2000) and Fee, Hadlock, and Thomas (2006) show that MS can mitigate incomplete contracts and thereby facilitate cooperation between independent firms, while Parker Ouimet (2013) finds that MS acquisitions are more common when it is efficient to keep the target's managerial incentives intact, and when the acquirer wishes to provide the target with financing or certify it to outside investors. We wish to examine whether the introduction of a national LP has an effect on MS acquisitions even after these additional forces are controlled for.

In general, a count data model could be estimated with a (Quasi-Maximum Likelihood) Poisson model or with a Negative Binomial model. The Poisson model however is inappropriate for our data since we have significant Poisson overdispersion: when estimated by Poisson, the resulting

they examine merger after cartel breakdowns rather than after the introduction of an LP. Using a pooled sample of 84 European cartels, they find that mergers are more frequent post-cartel breakdown, especially in less concentrated markets. This finding is consistent with the notion that mergers are an attempt to re-establish collusive behavior, although they may be also driven by other considerations, such as the need for market restructuring, due to more intense post-cartel competition.

${ }^{15}$ Jovanovic and Wey (2014) study a model in the MS acquisition is a first step towards a full merger. 
conditional variance is approximately four times larger than the variance implied by a Poisson distribution. ${ }^{16}$ We will therefore apply negative binomial estimation. This choice is supported by model fit test presented in Tables A1a and A1b in the Appendix. ${ }^{17}$

A potential source for the observed overdispersion is the fact that $30 \%$ of all observations in our data are zeros, i.e., country-year pairs without any MS acquisitions. This fraction of zeros is higher than assumed by Poisson and even higher than assumed by negative binomial models. It is possible that at least some of the zeros in our data are "false zeros" and are due to imperfect data reporting, especially in smaller and developing countries. Moreover, it is highly likely that data collection has improved over time so we have more false zeros in earlier years. To account for the problem we will therefore use a zero-inflated negative binomial (ZINB) model, which, in addition to the count component that estimates the full range of the counts, also contains a binary component that estimates the probability of excess zeros. The binary component, sometimes called the inflation equation, is conventionally computed using the following logit process:

$$
\operatorname{Pr}\left(M S_{i t}=0 \mid \mathbf{Z}_{i t}\right)=\frac{\exp \left(\boldsymbol{\beta} \mathbf{Z}_{i t}\right)}{1+\exp \left(\boldsymbol{\beta} \mathbf{Z}_{i t}\right)},
$$

where $\mathbf{Z}_{i t}$ is a vector of variables that may or may not coincide with variables used in the count component. ${ }^{18}$ In our case, we include in $\mathbf{Z}_{i t}$ three time dummies, for the periods 1990-1995, 19962000, and 2000-2013, as well as real GDP, real GDP per capita, and the size of the stock market. The last three variables are meant to capture the degree to which the country is developed, since we expect more developed countries to have fewer false zeros due to data collection problems. ${ }^{19}$ The tests presented in Tables A1a and T1b in the Appendix indicate that the ZINB model fits the data best. In the Appendix we also present results for the standard negative binomial models (without zero-inflation); these models also provide a good fit to the data, though the results are similar to the ZINB models presented in the main text.

\section{The Data}

We constructed the data set used to study the relationship between the introduction of a national LP and MS acquisitions in several steps, outlined in Table A2 in the Appendix. First, we extracted from Thomson One Financial database information on all acquisitions with a final stake under $50 \%$ in 63 countries for the period 1990-2013. Second, we eliminated acquisitions for which the final stake is unknown to ensure that we only study MS acquisitions. Third, we eliminated share buybacks and

\footnotetext{
${ }^{16}$ The Poisson model assumes that the conditional variance and mean are equidispersed, i.e., $\operatorname{Var}(y \mid x)=E(y \mid x)$. However in our case, the Pearson dispersion statistic - the standard statistic for measuring dispersion - is approximately 4 when we estimate the models by Poisson, i.e., the variation in our data is four times larger than it should be under the Poisson assumption.

${ }^{17}$ The tests are based on information criteria and Likelihood-ratio test for nested and Vuong test for non-nested models. They show that the fit of Poisson models is very poor compared to negative binomial models.

${ }^{18}$ The inflation equation may also include predictors other than the count process (see, e.g., Hilbe, 2007, p. 74).

${ }^{19} \mathrm{We}$ also experimented with other variables and other time periods, but the results did not change by much. We also included year fixed effects, but the estimation did not converge; hence we decided to use three time periods instead.
} 
self-tenders, i.e., acquisitions where the acquirer and target are one and the same. In the fourth and fifth steps, we eliminated acquisitions where the acquirer or target are investors and investment offices according to their primary business description. These acquisitions are likely to be driven by investment considerations, which are unrelated to the issue that we focus on in this paper. Sixth, we eliminated from most of our analysis cross-border acquisitions, because in such acquisitions it is not clear which competition authority is in charge and hence which LP is relevant. Seventh, we also eliminated from most of our analysis non-horizontal acquisitions. An acquisition is classified as horizontal if the listed activities of the acquirer (or its parent company) and the target overlap in at least one 4-digit SIC code. Without an overlap, we classify the transaction as non-horizontal. Our final data covers 14,112 domestic horizontal MS acquisitions, of which 11,714 are new MS acquisitions, and 2,398 are increases of an already existing MS. In some of our robustness checks, we will also examine domestic non-horizontal MS and cross-border horizontal MS.

Our main dependent variables are two measures of MS acquisitions: the number of MS acquisitions in country $i$ and year $t$, and the aggregate deal volume of MS acquisitions in country $i$ and year $t$, measured in millions of constant 1990 USD. These were computed using GDP deflator data for the US provided by the International Monetary Fund (IMF), with 1990 as the base year. Figure 1 below shows the annual total number of transactions and aggregate volume of MS acquisitions over all countries for the period 1990 and 2013. It is worth noting that the number of MS acquisitions and their aggregate volume have an increasing time trend with peaks in 2000 (the dotcom bubble) and in 2009 (the global financial crisis). ${ }^{20}$ In our analysis, we will therefore include time fixed effects to control for these trends.

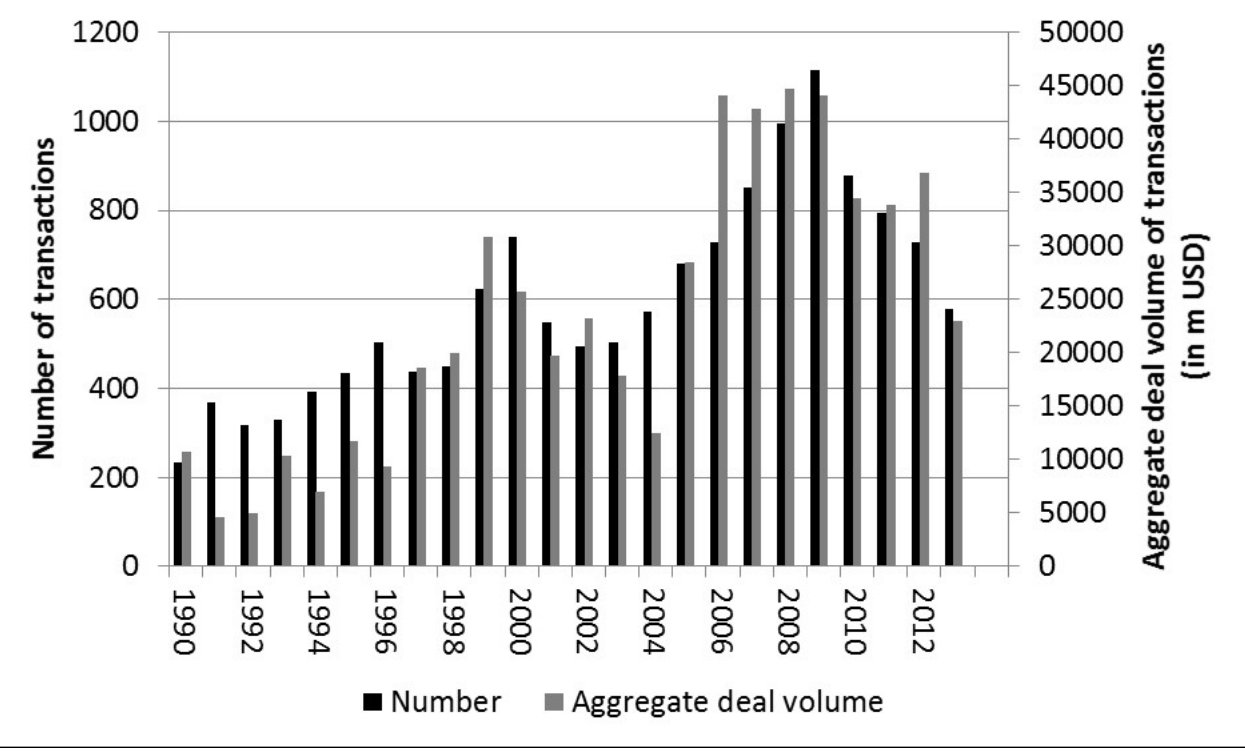

Figure 1: Number and aggregate volume of MS acquisitions (in million USD, 1990-2013)

\footnotetext{
${ }^{20}$ The increasing trend in the data might be due to improvements in the scope and quality of the used database.
} 
Of the countries in our data, the U.S. accounts for the largest aggregate volume of transactions, with about $18 \%$ of the total $(75,433$ million USD out of 430, 208 million USD), while Japan has the largest number of acquisitions, followed by the U.S. (1, 888 acquisitions in Japan and 1,680 in the U.S. out of a total of 14,112 MS acquisitions). The distributions of the number and aggregate volume of MS acquisitions across countries for the period 1990-2013 are presented in Figure A1 and A2 in the Appendix.

Of the 63 countries in our dataset, only 54 have introduced a national LP between 1993 and 2012 (Table A3 in the Appendix lists for each year, which countries have introduced an LP in that year). Argentina, Hong Kong, Indonesia, Jordan, Nigeria, Oman, Thailand, Venezuela, and Vietnam did not introduce an LP at least until 2013 when our data ends. The next figure shows the distribution of years in which LPs were introduced.

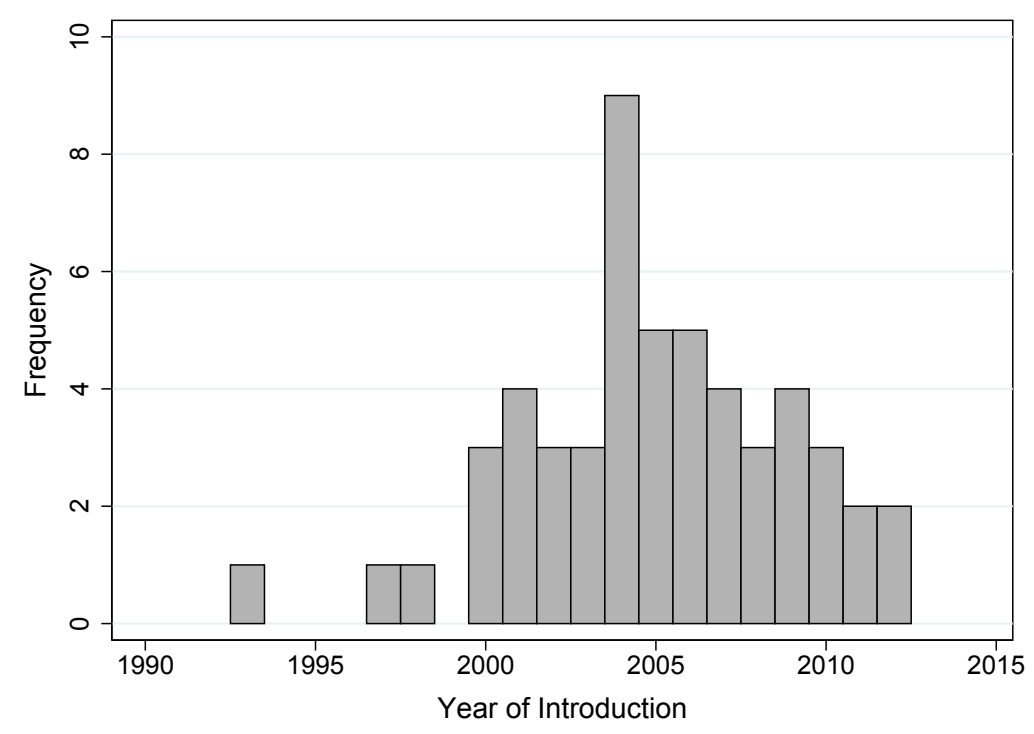

Figure 2: Frequency of the introduction of new national LP (by year)

The first countries to introduce an LP were the U.S., South Korea, and the U.K. After 2000, we see a significant increase in the introduction of LPs, with at least three countries introducing an LP each year. The peak was reached in 2004, with nine countries adopting an LP that year. ${ }^{21}$

As mentioned earlier, an LP may be ineffective in countries with weak antitrust enforcement and high levels of corruption. If so, the introduction of an LP should have no effect on MS acquisitions in such countries. To control for the efficacy of antitrust enforcement, we use the Anti-Monopoly Policy Index (AMPI), provided by the World Economic Forum (WEF) and published annually in the Global Competition Review (GCR). ${ }^{22}$ The AMPI is based on a survey of top business executives regarding their perception of the efficacy of antimonopoly policy in their particular country and

\footnotetext{
${ }^{21}$ The EU has introduced an LP in 1996 and revised in in 2002 and 2006. In this paper however we only focus on national LP's. Including the EU's LP and its revisions in the regressions does not change our qualitative results.

${ }^{22}$ The AMPI is part of a much broader Global Competitiveness Index (GCI), which can be downloaded at http://reports.weforum.org/global-competitiveness-report-2014-2015/rankings/ (last accessed on 24 June 2017). For the construction of AMPI, we use the variable "6.03 Effectiveness of anti-monopoly policy."
} 
varies from 1 (not effective at all) to 7 (extremely effective). The average AMPI values for the countries in our data set are shown in Table A3 in the Appendix. Although the AMPI is based on a single survey question and hence is unlikely to capture different dimensions of competition law and policy, we chose it over other popular measures, such as the GCR Rating Enforcement measure (RE), ${ }^{23}$ because of its wide coverage, which allows us to include it for 62 out of 63 countries in our data. Despite its simplicity, the AMPI is highly correlated with the RE measure, with a correlation coefficient of 0.7 . We therefore believe that the AMPI is a sensible measure of antitrust enforcement.

Since the AMPI is only available from 2006 onwards, we divide countries into two groups, depending on their average AMPI's during the 2006-2013 period. Countries with an average AMPI above the median for all countries are classified as having an effective antitrust enforcement, while countries with an average AMPI below the median are classified as having an ineffective antitrust enforcement. This classification is justified by the fact the AMPI scores are stable over time.

We control for corruption using the Corruption Perception Index (CPI), computed annually by Transparency International (TI). The CPI is based on survey-type assessments by analysts, businessmen, and experts and reflects the perceived level of corruption in the public sectors of their country. It rates countries on a 10 points scale, with a higher score reflecting a lower level of corruption. $^{24}$ The average CPI values for the countries in our data set are shown in Table A3 in the Appendix. Unfortunately, we do not have CPI scores for all country-year pairs since CPI were originally available only for 28 countries out of the 63 countries in our sample and is available only for 42 countries from 2003 onwards. We therefore exploit the fact that the CPI for each country is stable over time, and as in the AMPI case, classify countries as having either a low or a high level of corruption, depending on whether their average CPI scores are below or above the median for all countries.

To control for other potential determinants of MS acquisitions, we collected country-specific macroeconomic variables, including GDP growth, real GDP per capita, unemployment rate, inflation rate (based on the GDP deflator index), and the purchasing-power-parity conversion rate (PPPEX). These variables were shown to be potential drivers of mergers and acquisitions (see, e.g., Rossi and Volpin (2003), Di Giovanni (2005) and Erel et al. (2012)). We also include a real GDP variable to control for country size, and the growth rate of the volume of import (IMP) and exports (EXP) of goods and services to reflect year-over-year changes in trade activity. All these variables are taken from the World Economic Outlook Database (WEO) provided by the International Monetary Fund (IMF) and are available for all countries in our data except India and Oman.

In addition to the macroeconomic control variables, we also include in the analysis countryspecific financial markets variables from the World Bank's World Development Indicators (WDI).

\footnotetext{
${ }^{23}$ The RE measure is based on a detailed questionnaire filled by the competition authorities themselves (e.g. size of the authority, their methodologies for setting priorities and ensuring transparency as well as a detailed breakdown of the number and the handling of merger filings and their cartel and abuse of dominance work). In addition, the RE measure also considers how local competition counsels, antitrust lawyers and economists, academics, and local journalists evaluate an agency's performance. However, the RE measure is only available for a fraction of the countries used in our analysis.

${ }^{24}$ For further information on the CPI, see http://www.transparency.org/research/cpi/overview (last accessed on 24 June 2017).
} 
These variables include the total market capitalization of listed firms as a share of the GDP to control for the size of the stock market (STOCK); domestic credit to private sector as a share of the GDP to control for the availability of credit (CREDIT); the trade ratio as the share of total imports and exports in GDP to control for trade activity (TRADE); and the real interest rate, which is the lending interest rate adjusted for inflation, to control for the real cost of investment (INTEREST). Unfortunately, the financial markets variables (and especially CREDIT and INTEREST) are not available for all country-year pairs and hence when we use them, our sample is reduced from 1,368 to 1,018 country-year pairs.

Table 1 shows the summary statistics of our variables, reported on an annual basis.

Table 1: Descriptive statistics

\begin{tabular}{lllllll}
\hline & Mean & S.D. & Min & Max & Obs. & Source \\
\hline No. of MS acquisitions & 8.62 & 19.1 & 0 & 189 & 1500 & Thomson \\
No. of new MS acquisitions & 7.13 & 15.4 & 0 & 151 & 1500 & Thomson \\
Aggregate volume of MS acquisitions & 144 & 380 & 0 & 4225 & 1500 & Thomson \\
Aggregate volume of new MS acquisitions & 112 & 309 & 0 & 3929 & 1500 & Thomson \\
Real GDP & 4.85 & 1.6 & 0.39 & 9.24 & 1477 & IMF \\
GDP growth & 0.03 & 0.0 & -0.23 & 0.24 & 1468 & IMF \\
Real GDP per capita (in m USD) & 8.83 & 1.3 & 4.59 & 11.2 & 1473 & IMF \\
Unemployment (\% of Labor Force) & 7.95 & 4.6 & 0.03 & 27.8 & 1397 & IMF \\
Inflation (\%) & 28.3 & 230 & -25.70 & 5053 & 1466 & IMF \\
Purchasing-power-parity conversion rate (PPPEX) & 115 & 530.9 & 0.00 & 7311 & 1472 & IMF \\
Volume of exports of goods and services (EXP) & 7.58 & 7.9 & -26.6 & 77.5 & 1451 & IMF \\
Volume of imports of goods and services (IMP) & 9.81 & 17.1 & -41.6 & 507 & 1453 & IMF \\
Credit (\% of GDP) & 73.5 & 50.9 & 1.12 & 311 & 1373 & WDI \\
Interest rate (\%) & 5.89 & 11.3 & -91.7 & 93.9 & 1190 & WDI \\
Stock (\% of GDP) & 59.5 & 64.9 & 0.00 & 606 & 1375 & WDI \\
Trade (\% of GDP) & 85.5 & 65.6 & 13.8 & 450 & 1437 & WDI \\
Anti-Monopoly Policy Index (AMPI, 1-7) & 4.51 & 0.7 & 2.84 & 5.77 & 1476 & TI \\
Corruption Perception Index (CPI, 1-10) & 6.25 & 2.2 & 2.44 & 9.48 & 996 & WEF \\
\hline
\end{tabular}

Notes: All variables reflecting a percentage are scaled to 100 for $100 \%$; Volumes of acquisitions and GDP are measured in constant 1990 million USD; GDP growth and imports and exports are measured in year-on-year percentage changes.

Table 1 shows that on average, there are 8.6 national horizontal MS acquisitions per country per year, of which 7.1 are new acquisitions. The average aggregate deal volume is 144 million USD for all acquisitions, and 112 million USD for new acquisitions. Both the number and volume of MS acquisitions have a large variance. In particular, in $30 \%$ of all country-year pairs in our data there are no MS acquisitions, while in other country-year pairs there is a large number and a large 
volume of MS acquisitions. The table also shows a large diversity across countries in terms of the macroeconomic and the financial market variables: for example, the average unemployment rate ranges from $0.3 \%$ (Switzerland, 1990) to $27.8 \%$ percent (South Africa, 2002), inflation rates vary from $-26 \%$ (Oman, 2009) to more than $5,000 \%$ (Peru, 1990), credit ranges from $1.1 \%$ of GDP (the Slovak Republic in 2006) to $311 \%$ of GDP (Iceland in 2006), and the real interest rate ranges from $-92 \%$ (Ukraine in 1993) to $94 \%$ (Bulgaria in 1996). ${ }^{25}$

Before moving to the estimation results, we first illustrate in Figure 3 the evolution of the number and aggregate volume of domestic horizontal MS acquisitions from three years before the introduction of a national LP to three years after. To make the data comparable across countries, we normalize the data for each country to values between 0 and 1 , as follows:

$$
M S_{i t}^{n o r m}=\frac{M S_{i t}-\min \left(M S_{i}\right)}{\max \left(M S_{i}\right)-\min \left(M S_{i}\right)},
$$

where $\min \left(M S_{i}\right)$ and $\max \left(M S_{i}\right)$ are the lowest and highest value of $M S_{i t}$ for country $i$ over the sample period. Cyprus, Ecuador, Taiwan and Ukraine are not included in the figure since they introduced a national LP only in 2011 and 2012, respectively, so we do not have observations on full three years after the LP was introduced (we have data only until 2013).
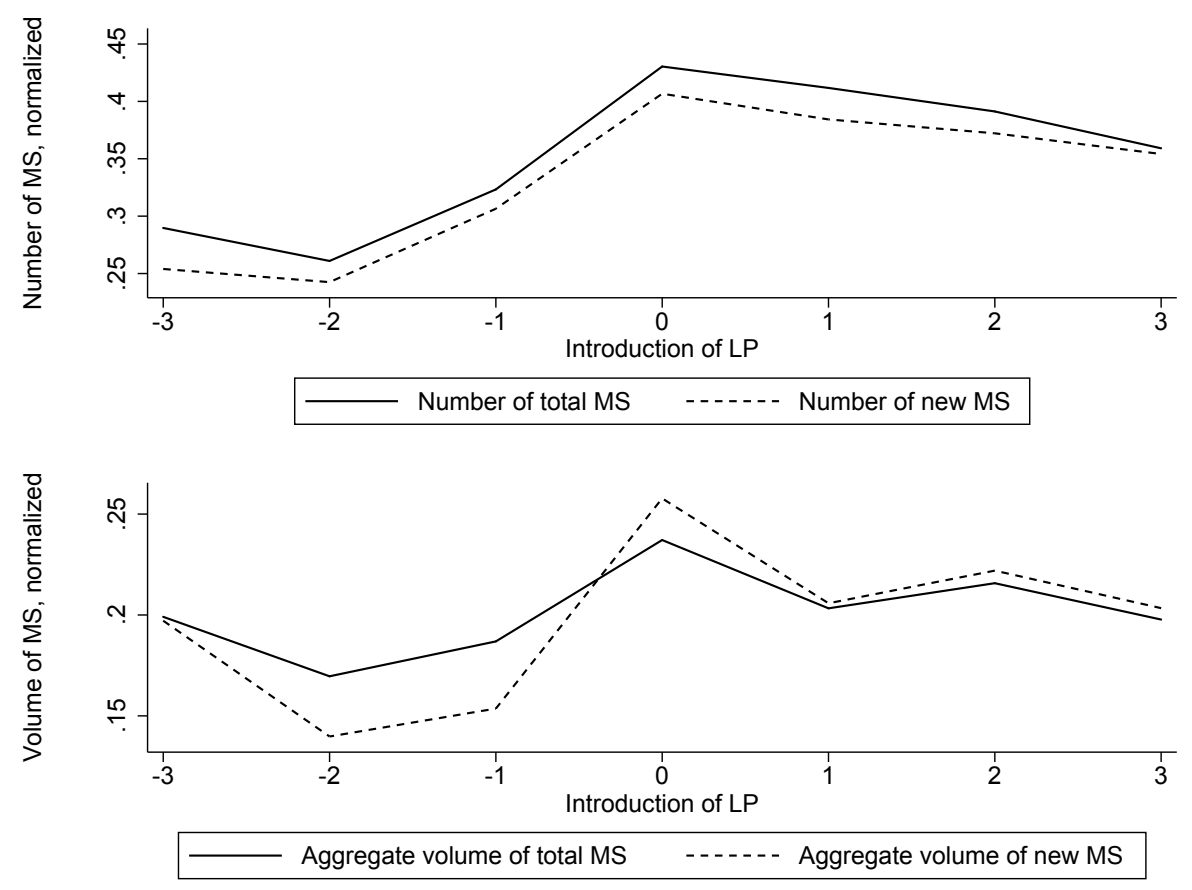

Figure 3: Development of MS acquisitions in the three years before and after the introduction of national leniency programs (normalized by country, 0-1)

\footnotetext{
${ }^{25}$ Some values in Table 1 are extreme, like the minimum value of GDP growth of -920.7 , which correspondes to Bulgaria in 1991, immediately after the fall of communism in Eastern Europe.
} 
Figure 3 shows that the number of MS acquisitions, as well as their aggregate volume, increase as we approach the year in which an LP is introduced (this year is different for different countries) and then decrease. This trend suggests that the introduction of an LP encourages MS acquisitions in rivals. In the next section, we show that this pattern persists even after we control for various factors that may affect MS acquisitions, and use year fixed effects.

\section{Estimation Results}

We present our estimation results for the number of new domestic MS acquisitions in rivals and their aggregate deal volumes Tables 2 and 3 below. The results are obtained from ZINB estimation. In the online Appendix, we present corresponding results from negative binomial estimation; the results are very similar to those in Tables 2 and 3. In all specifications, we include country and year fixed effects. In most of the paper we only focus on new MS acquisitions in domestic rivals. Including increases of already existing MS shareholdings in rivals, yields very similar results, especially for the number of MS acquisitions. The results for this case are also in the online Appendix. 
Table 2: ZINB estimations of the number of new domestic horizontal MS acquisitions

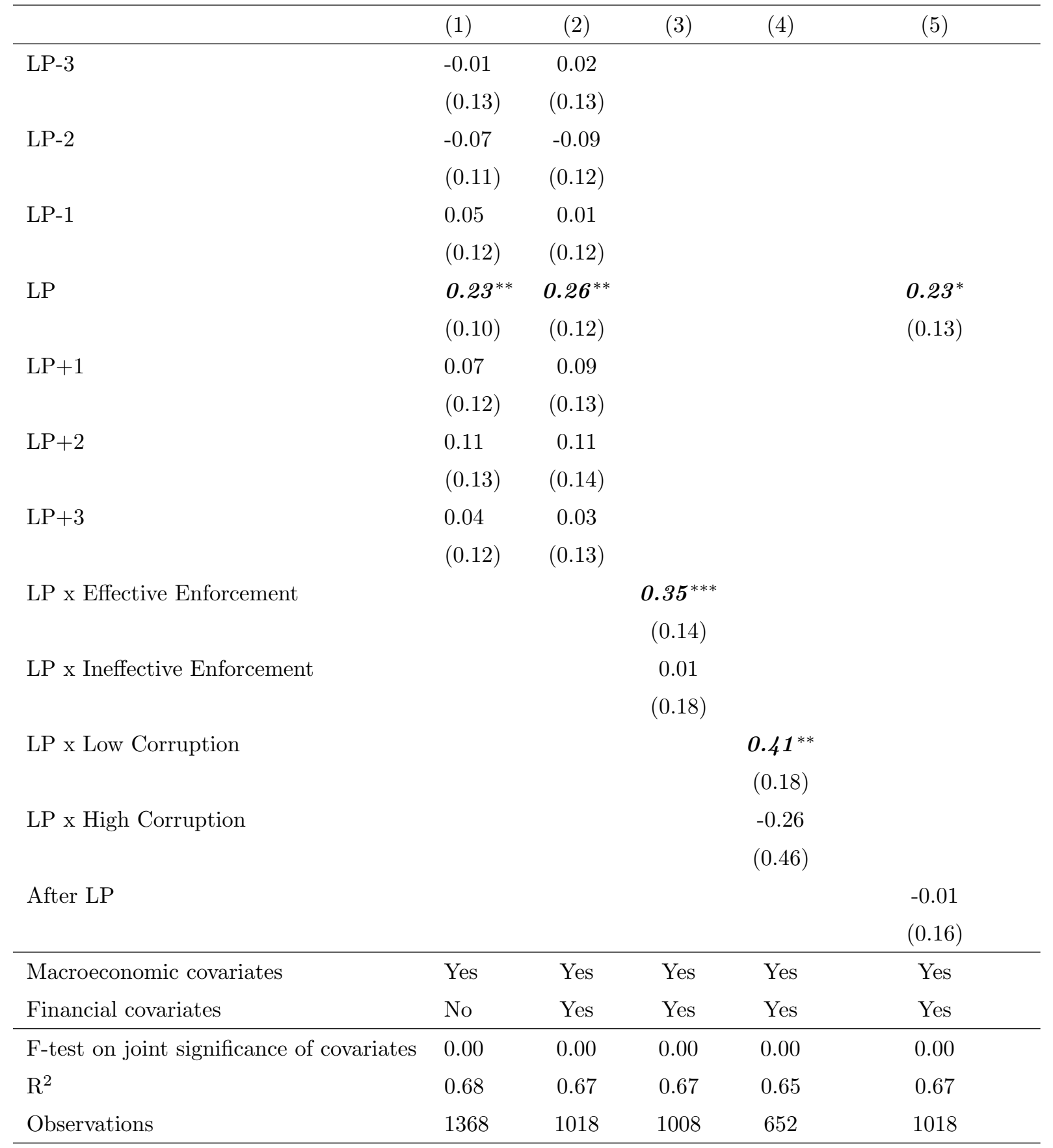

Notes: S.E. clustered at the country-level. Inflation equation is reported in the online Appendix. All specifications include year and country fixed effects. The macroeconomic covariates are GDP, GDP growth, GDP per capita, Unenmployment rate, Inflation, PPPEX, IMP and EXP. The financial covariates are CREDIT, INTEREST, STOCK and Trade. All covariates are lagged by one year. The full estimation outputs are available in the online Appendix of the paper. The reported $\mathrm{R}^{2}$ is the deviance based $\mathrm{R}^{2}$ suggested by Cameron and Windmeijer (1996). ${ }^{*} \mathrm{p}<0.10 ;{ }^{* *} \mathrm{p}<0.05 ;{ }^{* * *} \mathrm{p}<0.01$ 
Columns (1) and (2) in Table 2 show that the number of new domestic horizontal MS acquisitions increases significantly by $26 \%-30 \%$ in the year in which an LP was introduced. ${ }^{26}$ Note that Column (1) does not include the financial market variables, which are not available for all country-year pairs, and therefore has more observations. Yet the results in Columns (1) and (2) are very similar. The increase in the number of new domestic horizontal MS acquisitions is consistent with the idea that firms acquires MS in rivals to stabilize collusive arrangements that were destabilized by the introduction of an LP. Alternatively, it could be that firms anticipate that the LP will lead to a collapse of their collusive agreement, so they acquire MS in rivals in order to make the non-collusive equilibrium that will prevail less competitive.

In Column (5) we examine this issue further by replacing the before/after LP year dummies with a single "After LP" dummy that takes the value 1 in all years after an LP was introduced and 0 otherwise (including the year in which the LP was introduced). The idea is to examine whether an LP has a permanent effect on MS acquisitions. It turns out, however, that the "After LP" dummy is not significant, suggesting that the effect of LP on MS is indeed limited to the year at which the LP was introduced. A potential reason for this is that an LP may deter new cartels from being formed, and hence firms do not need to acquire MS in rivals either. Yet, firms need to stabilize their existing collusive agreements once an LP is introduced, and hence they respond quickly to the introduction of the LP by acquiring MS in the year in which the LP is first introduced.

In Columns (3) and (4), we interact the LP dummy with the AMPI and the CPI to control for the efficacy of antitrust enforcement. Since the AMPI and CPI are not available for all countryyear pairs, we have fewer observations in Columns (3) and especially (4). The results show that the effect of the introduction of an LP on MS acquisitions is limited to countries with effective antitrust enforcement and low levels of corruption. The effect in these countries is in fact much larger than it is for the entire set of countries: the number of MS acquisitions in these countries is $42 \%-51 \%$ higher in the year an LP is introduced than in other years. ${ }^{27}$ The finding that the introduction of an LP affects MS acquisitions only in countries with effective antitrust enforcement and low levels of corruption is consistent with the idea that when antitrust enforcement is weak and/or the level of corruption is high, an LP is either unlikely to be effective in destabilizing collusive agreements or collusion is feasible even without the need to acquire MS in rivals. Hence, the introduction of an LP has no effect on new MS acquisitions in such countries.

We now turn to the aggregate deal volume of new domestic horizontal MS acquisitions. The results are presented in Table 3 .

\footnotetext{
${ }^{26}$ The exponentiated coefficients of 0.23 in Column (1) and 0.26 in Column (2) are 1.26 and 1.30, and therefore represent an increase of $26 \%$ and $30 \%$ in MS acquisitions in the year an LP was introduced.

${ }^{27}$ The exponentiated coefficients of 0.35 in Column (3) and 0.41 in Column (4) are 1.42 and 1.51.
} 
Table 3: ZINB estimations of the aggregate volume of new domestic horizontal MS acquisitions

\begin{tabular}{|c|c|c|c|c|c|}
\hline & $(1)$ & (2) & (3) & $(4)$ & (5) \\
\hline \multirow[t]{2}{*}{ LP-3 } & 0.15 & 0.10 & & & \\
\hline & $(0.46)$ & $(0.43)$ & & & \\
\hline \multirow[t]{2}{*}{ LP-2 } & 0.01 & -0.00 & & & \\
\hline & $(0.32)$ & $(0.36)$ & & & \\
\hline \multirow[t]{2}{*}{ LP-1 } & -0.23 & -0.26 & & & \\
\hline & $(0.35)$ & $(0.40)$ & & & \\
\hline \multirow[t]{2}{*}{ LP } & $0.56^{* *}$ & $0.71^{* *}$ & & & $0.93^{* *}$ \\
\hline & $(0.29)$ & $(0.29)$ & & & $(0.39)$ \\
\hline \multirow[t]{2}{*}{$\mathrm{LP}+1$} & 0.26 & $0.56^{* *}$ & & & \\
\hline & $(0.25)$ & $(0.23)$ & & & \\
\hline \multirow[t]{2}{*}{$\mathrm{LP}+2$} & 0.30 & 0.42 & & & \\
\hline & $(0.27)$ & $(0.26)$ & & & \\
\hline \multirow[t]{2}{*}{$\mathrm{LP}+3$} & 0.35 & 0.29 & & & \\
\hline & $(0.38)$ & $(0.45)$ & & & \\
\hline \multirow[t]{2}{*}{ LP x Effective Enforcement } & & & $1.14^{* * *}$ & & \\
\hline & & & $(0.44)$ & & \\
\hline \multirow[t]{2}{*}{ LP x Ineffective Enforcement } & & & -0.26 & & \\
\hline & & & $(0.48)$ & & \\
\hline \multirow[t]{2}{*}{ LP x Low Corruption } & & & & $0.89^{* *}$ & \\
\hline & & & & $(0.38)$ & \\
\hline \multirow[t]{2}{*}{ LP x High Corruption } & & & & -0.36 & \\
\hline & & & & $(0.51)$ & \\
\hline \multirow[t]{2}{*}{ After LP } & & & & & $0.63^{*}$ \\
\hline & & & & & $(0.33)$ \\
\hline Macroeconomic covariates & Yes & Yes & Yes & Yes & Yes \\
\hline Financial covariates & No & Yes & Yes & Yes & Yes \\
\hline F-test on joint significance of covariates & 0.00 & 0.00 & 0.00 & 0.00 & 0.00 \\
\hline $\mathrm{R}^{2}$ & 0.33 & 0.35 & 0.35 & 0.36 & 0.36 \\
\hline Observations & 1368 & 1018 & 1008 & 652 & 1018 \\
\hline
\end{tabular}

Notes: S.E. clustered at the country-level. Inflation equation is reported in the online Appendix. All specifications include year and country fixed effects. Covariates are included as in Table 2 but not reported. ${ }^{*} \mathrm{p}<0.10 ;{ }^{* *} \mathrm{p}<0.05 ;{ }^{* * *} \mathrm{p}<0.01$ 
The results in Table 3 are qualitatively similar to those in Table 2. The coefficients of the leniency dummy in Columns (1) and (2) indicate a $75 \%-103 \%$ increase in the aggregate deal volume of domestic horizontal MS acquisitions in the year at which the LP is introduced. ${ }^{28}$ Moreover, Column (2) shows that the aggregate deal volume of MS acquisitions also increases in the first year after the introduction of the LP.

Note that the LP coefficient is much larger in Table 3 than in Table 2, indicating that the introduction of an LP has a much larger effect on the deal volume of MS acquisitions than on their sheer number. That is, after an LP is in place, firms pay on average more money for MS stakes in rivals. There are two potential reasons for this: (i) firms may buy larger stakes in rivals once an LP is introduced and hence they pay more, and (ii) firms may acquire stakes in larger rivals, which require higher payments.

Before we examine this issue in detail, we first take a closer look at the size of MS stakes that firms acquire. To this end, we split the MS acquisitions in our data into five groups, depending on the size of the acquired stake: up to $10 \%, 10 \%-20 \%, 20 \%-30 \%, 30 \%-40 \%$, and $40 \%-50 \%$. Table 4 shows the distribution of MS acquisitions by the size of the acquired stake in millions of USD.

Table 4: Size intervals of domestic horizontal MS acquisitions (1990-2013)

\begin{tabular}{|c|c|c|c|c|c|c|c|c|}
\hline $\begin{array}{c}\text { Size } \\
\text { Interval }\end{array}$ & $\begin{array}{l}\text { Number } \\
\text { New MS }\end{array}$ & $\%$ & $\begin{array}{c}\text { Number MS } \\
\text { Increases }\end{array}$ & $\%$ & $\begin{array}{c}\text { Volume New MS } \\
\text { (in m USD) }\end{array}$ & $\%$ & $\begin{array}{l}\text { Volume MS Increases } \\
\text { (in m USD) }\end{array}$ & $\%$ \\
\hline $0-10 \%$ & 2,345 & 20 & 1,201 & 50 & 35,684 & 21 & 20,985 & 44 \\
\hline $10-20 \%$ & 2,899 & 25 & 745 & 31 & 40,700 & 24 & 13,412 & 28 \\
\hline $20-30 \%$ & 2,537 & 22 & 308 & 13 & 35,497 & 21 & 8,289 & 17 \\
\hline $30-40 \%$ & 1,775 & 15 & 90 & 4 & 25,633 & 15 & 3,700 & 8 \\
\hline $40-50 \%$ & 1,948 & 17 & 23 & 1 & 31,204 & 18 & 1,101 & 2 \\
\hline Total & 11,504 & 100 & 2,398 & 100 & 168,718 & 100 & 47,587 & 100 \\
\hline
\end{tabular}

Table 4 shows that the number of new MS acquisitions and their volume are by and large evenly split among the five groups, though acquisitions of $10 \%-20 \%$ stakes are more common than acquisitions of large stakes of $30 \%$ or more. With MS increases, the majority of acquisitions are of less than $20 \%$ and especially less than $10 \% .^{29}$ Since we restrict attention to financial stakes under $50 \%$, the latter result is not surprising since the acquired stakes are constrained by the size of the exsisting stakes (for example, a firm that already holds $20 \%$ in a rival can acquire at most $30 \%$ without turning its stake into a majority stake).

\footnotetext{
${ }^{28}$ The exponentiated coefficients of 0.56 in Column (1) and 0.71 in Column (2) are equal to 1.75 and 2.03.

${ }^{29}$ If we consider the final stake of the acquirer after the acquisition rather than the size of the acquired stake, then $9 \%$ of all acquisitions have a final stake of up to $10 \%, 24 \%$ have a final stake of $10 \%-20 \%, 24 \%$ have a final stake of $20 \%-30 \%, 21 \%$ have a final stake of $30 \%-40 \%$, and $22 \%$ have a final stake of $40 \%-50 \%$. The median size of the initial stake before the acquisition of an additional stake is around $13 \%$.
} 
Table 5: ZINB estimations of the number of new domestic horizontal MS acquisitions by stake size

\begin{tabular}{|c|c|c|c|c|c|}
\hline & (1) & (2) & (3) & (4) & (5) \\
\hline & $0-10 \%$ & $10-20 \%$ & $20-30 \%$ & $30-40 \%$ & $40-50 \%$ \\
\hline \multirow[t]{2}{*}{ LP-3 } & -0.25 & 0.15 & 0.09 & 0.08 & 0.19 \\
\hline & $(0.24)$ & $(0.23)$ & $(0.15)$ & $(0.13)$ & $(0.12)$ \\
\hline \multirow[t]{2}{*}{ LP-2 } & -0.19 & 0.00 & 0.16 & -0.18 & -0.32 \\
\hline & $(0.16)$ & $(0.19)$ & $(0.13)$ & $(0.21)$ & $(0.20)$ \\
\hline \multirow[t]{2}{*}{ LP-1 } & -0.17 & 0.23 & -0.12 & -0.21 & -0.10 \\
\hline & $(0.17)$ & $(0.17)$ & $(0.18)$ & $(0.19)$ & $(0.21)$ \\
\hline \multirow[t]{2}{*}{ LP } & 0.13 & $0.53^{* * *}$ & -0.09 & -0.28 & 0.20 \\
\hline & $(0.20)$ & $(0.20)$ & $(0.14)$ & $(0.20)$ & $(0.22)$ \\
\hline \multirow[t]{2}{*}{$\mathrm{LP}+1$} & 0.14 & 0.18 & 0.08 & 0.16 & 0.06 \\
\hline & $(0.17)$ & $(0.18)$ & $(0.14)$ & $(0.12)$ & $(0.16)$ \\
\hline \multirow[t]{2}{*}{$\mathrm{LP}+2$} & 0.16 & 0.23 & 0.17 & 0.17 & $0.30^{* *}$ \\
\hline & $(0.20)$ & $(0.20)$ & $(0.17)$ & $(0.17)$ & $(0.14)$ \\
\hline \multirow[t]{2}{*}{$\mathrm{LP}+3$} & 0.22 & 0.23 & 0.04 & -0.06 & -0.04 \\
\hline & $(0.20)$ & $(0.17)$ & $(0.17)$ & $(0.15)$ & $(0.18)$ \\
\hline Macroeconomic covariates & Yes & Yes & Yes & Yes & Yes \\
\hline Financial covariates & Yes & Yes & Yes & Yes & Yes \\
\hline F-test & 0.00 & 0.00 & 0.00 & 0.00 & 0.00 \\
\hline $\mathrm{R}^{2}$ & 0.57 & 0.57 & 0.57 & 0.52 & 0.51 \\
\hline Observations & 1018 & 1018 & 1018 & 1018 & 1018 \\
\hline
\end{tabular}

Notes: S.E. clustered at the country-level. Inflation equation is reported in the online Appendix. All specifications include year and country fixed effects. The macroeconomc and financial covariates are as in Table 2. ${ }^{*} \mathrm{p}<0.10 ;{ }^{* *} \mathrm{p}<0.05 ;{ }^{* * *} \mathrm{p}<0.01$

In Table 5, we present results from estimating the same specification as in Column (2) in Table 2, but now separately for each of the five size groups. The results show that in the year an LP is introduced, the effect on new domestic horizontal MS acquisitions is concentrated on acquisitions of a $10 \%-20 \%$ stake in rivals, but not in other size groups. Stakes that are under $20 \%$ typically do not trigger merger notification and hence can go "under the radar." Clearly, colluding firms would prefer such stakes over larger stakes that do trigger merger notification and antitrust scrutiny. Interestingly, we also find a significant effect for larger acquisitions of $40 \%-50 \%$ two years after the introduction of an LP. It turns out that this effect is driven by MS acquisitions in the U.S.: once the U.S. is dropped from the sample, the effect disappears. ${ }^{30}$

We now turn to the question posed earlier: why is there an increase in the volume of MS

\footnotetext{
${ }^{30}$ The U.S. adjusted their 1993 LP in 1995 (see Sovinsky and Helland (2012)). Of the 1, 948 MS acquisitions which involve stakes of $40 \%-50 \%$ (see Table 4), 202 are from the U.S.
} 
acquisitions after an LP is introduced? Is this because, on average, firms acquire larger stakes in rivals, or because, on average, they acquire stakes in larger rivals? To provide an answer, we begin by studying the effect that the introduction of an LP has on the aggregate MS stake that firms acquire in domestic rivals. That is, the dependent variable now is the unweighted sum of all acquired stakes in country $i$ and year $t$. For example, if there are two MS acquisitions in country $i$ in year $t$, one of a $10 \%$ stake and the other of a $30 \%$ stake, then the aggregate stake size is $40 \%$. The estimates, presented in Table A4 in the Appendix, suggest that despite the increase in the number and volume of domestic horizontal MS acquisitions, the introduction of an LP does not have a significant effect on the aggregate stake which is acquired (the effect is significant only in Column (1) where we do not control for financial covariates). Hence, the increase in the volume of MS acquisitions is not due to acquisitions of larger stakes once an LP is in place.

Having ruled out the possibility that firms acquire larger stakes, we now examine the possibility that once an LP is in place, firms acquire stakes in larger rivals. To this end, we measure the size of the target firms in terms of their market capitalization, which is defined as follows:

$$
\text { Market Cap }=100 \times \frac{\text { Deal volume }}{\text { Acquired stake }} \text {. }
$$

We then split the target firms into two groups, small and large, depending on whether their market capitalization is below or above the median of all target firms in their country. The results appear in Table 6. The dependent variable is the number of MS acquisitions in small rivals in Columns (1)-(4) and in large rivals in Columns (5)-(8). 
Table 6: ZINB estimations of the number of new domestic horizontal MS acquisitions by rival size

\begin{tabular}{|c|c|c|c|c|c|c|c|c|}
\hline & $(1)$ & $(2)$ & $(3)$ & $(4)$ & $(5)$ & $(6)$ & $(7)$ & $(8)$ \\
\hline & \multicolumn{4}{|c|}{ Small Firms } & \multicolumn{4}{|c|}{ Large Firms } \\
\hline \multirow[t]{2}{*}{ LP-3 } & 0.09 & & & & 0.05 & & & \\
\hline & $(0.17)$ & & & & $(0.13)$ & & & \\
\hline \multirow[t]{2}{*}{ LP-2 } & 0.09 & & & & -0.14 & & & \\
\hline & $(0.16)$ & & & & $(0.14)$ & & & \\
\hline \multirow[t]{2}{*}{ LP-1 } & 0.13 & & & & -0.05 & & & \\
\hline & $(0.15)$ & & & & $(0.13)$ & & & \\
\hline \multirow[t]{2}{*}{ LP } & -0.01 & & & -0.08 & $0.32^{* *}$ & & & $0.35^{* *}$ \\
\hline & $(0.17)$ & & & $(0.19)$ & $(0.14)$ & & & $(0.14)$ \\
\hline \multirow[t]{2}{*}{$\mathrm{LP}+1$} & 0.11 & & & & 0.12 & & & \\
\hline & $(0.14)$ & & & & $(0.13)$ & & & \\
\hline \multirow[t]{2}{*}{$\mathrm{LP}+2$} & 0.06 & & & & 0.17 & & & \\
\hline & $(0.21)$ & & & & $(0.13)$ & & & \\
\hline \multirow[t]{2}{*}{$\mathrm{LP}+3$} & -0.04 & & & & 0.08 & & & \\
\hline & $(0.15)$ & & & & $(0.14)$ & & & \\
\hline \multirow[t]{2}{*}{ LP x Effective Enforcement } & & 0.01 & & & & $0.40^{* * *}$ & & \\
\hline & & $(0.18)$ & & & & $(0.14)$ & & \\
\hline \multirow[t]{2}{*}{ LP x Ineffective Enforcement } & & -0.20 & & & & 0.02 & & \\
\hline & & $(0.26)$ & & & & $(0.22)$ & & \\
\hline \multirow[t]{2}{*}{ LP x Low Corruption } & & & 0.14 & & & & $0.46^{* * *}$ & \\
\hline & & & $(0.19)$ & & & & $(0.17)$ & \\
\hline \multirow[t]{2}{*}{ LP x High Corruption } & & & 0.03 & & & & $-0.48^{*}$ & \\
\hline & & & $(0.33)$ & & & & $(0.26)$ & \\
\hline \multirow[t]{2}{*}{ After LP } & & & & -0.06 & & & & 0.10 \\
\hline & & & & $(0.18)$ & & & & $(0.16)$ \\
\hline Macroeconomic covariates & Yes & Yes & Yes & Yes & Yes & Yes & Yes & Yes \\
\hline Financial covariates & Yes & Yes & Yes & Yes & Yes & Yes & Yes & Yes \\
\hline F-test & 0.00 & 0.00 & 0.00 & 0.00 & 0.00 & 0.00 & 0.00 & 0.00 \\
\hline $\mathrm{R}^{2}$ & 0.60 & 0.61 & 0.59 & 0.60 & 0.65 & 0.66 & 0.64 & 0.66 \\
\hline Observations & 1018 & 1008 & 652 & 1018 & 1018 & 1008 & 652 & 1018 \\
\hline
\end{tabular}

Notes: S.E. clustered at the country-level. Inflation equation is reported in the online Appendix. All specifications include year and country fixed effects. The macroeconomic and financial covariates are as in Table 2. ${ }^{*} \mathrm{p}<0.10 ;{ }^{* *} \mathrm{p}<0.05 ;{ }^{* * *} \mathrm{p}<0.01$ 
Table 6 shows that in the year in which a national LP is introduced, there is a significant increase in the number of MS acquisitions in large rivals, but not in small ones. Columns (6)-(7) show that the effect is present only in countries with an effective antitrust enforcement and low levels of corruption. Column (8) shows that the effect is present only in the year in which the LP is introduced, but not in subsequent years. The finding that the introduction of an LP encourages acquisitions of stakes in large rivals is consistent with Hellwig and Hüschelrath (2016), who find that large firms are often involved in cartel activity, and with Hoang et al. (2014), who find that large cartel members are most likely to become the chief witness under an LP. Unfortunately, we do not observe the size of the acquirers and therefore cannot investigate whether the introduction of LP also affects the acquirer's size.

\section{Robustness Checks}

We now report some robustness checks. We begin by looking at whether, beside its effect on new domestic horizontal (DH) MS acquisitions, the introduction of an LP also affected new domestic nonhorizontal (DNH) MS acquisitions (the acquirer and the target do not have any overlap in their SIC codes), new cross-border horizontal (CBH) MS acquisitions, and new cross-border non-horizontal $(\mathrm{CBNH}) \mathrm{MS}$ acquisitions. To this end, we now estimate the same model as before, except that we also add, separately each time, observations on DNH, CBH, and CBNH MS acquisitions, as a control group. We then estimate the following model for the number of new MS acquisitions:

$$
M S_{i t}=\exp \left(\boldsymbol{\alpha}_{1}\left(\mathbf{L P}_{i t} \times \mathbf{D H}\right)+\boldsymbol{\alpha}_{2}\left(\mathbf{L} \mathbf{P}_{i t} \times \mathbf{C G}\right)+\gamma D H+\boldsymbol{\beta} \mathbf{X}_{i t}+\xi_{i}+\xi_{t}+\varepsilon_{i t}\right),
$$

where $D H$ is a dummy that takes the value 1 if the observation for a certain country-year pair refers to new horizontal domestic MS acquisition and 0 otherwise, and $C G=1-D H$. We then estimate this model separately for each type of a control group. The results regarding the number of new MS acquisitions are reported in Table 7 below. ${ }^{31}$ In Column (1), the control group is DNH MS acquisitions, in Columns (2)-(3) it is CBH MS acquisitions, and in Columns (4)-(5) it is CBNH MS acquisitions. In the case of cross-border acquisitions, we examine separately cases in which the introduction of an LP is in the target's country (Columns (2) and (4)) and in which it is in the acquirer's country (Columns (3) and (5)).

The results show that the introduction of an LP has a significant effect only on domestic horizontal MS acquisitions, but not on other types of MS acquisitions. This finding is consistent with the idea that domestic horizontal MS acquisitions are driven, at least partly, by the desire to stabilize domestic collusive agreements.

\footnotetext{
${ }^{31}$ We also used the volume of MS acquisitions as a dependent variable. The results, available in an online Appendix, show that an LP has a significant positive effect only in the year it is introduced or one year after, but only in the case of domestic horizontal acquiesitions. An LP has no effect on domestic non-horizontal, cross-border horizontal, or cross-border non-horizontal MS aquisitions.
} 
Table 7: ZINB estimations for the number of new domestic horizontal MS acquisitions (DH) with different control groups (CG)

\begin{tabular}{|c|c|c|c|c|c|c|c|c|c|c|}
\hline & \multicolumn{2}{|l|}{$(1)$} & \multicolumn{2}{|l|}{$(2)$} & \multicolumn{2}{|l|}{ (3) } & \multicolumn{2}{|l|}{ (4) } & \multicolumn{2}{|l|}{ (5) } \\
\hline CG is: & DNH & & $\begin{array}{l}\mathrm{CBH}(\mathrm{LF} \\
\text { target co }\end{array}$ & $\begin{array}{l}\text { in } \\
\text { antry) }\end{array}$ & $\begin{array}{l}\text { CBH (LF } \\
\text { acquirer } \\
\text { country) }\end{array}$ & & $\begin{array}{l}\mathrm{CBNH}(\mathrm{I} \\
\text { target co }\end{array}$ & $\begin{array}{l}\text { CP in } \\
\text { untry) }\end{array}$ & $\begin{array}{l}\text { CBNH (I } \\
\text { acquirer } \\
\text { country) }\end{array}$ & \\
\hline $\mathrm{LP}-3 \times \mathrm{DH}$ & 0.04 & $(0.14)$ & 0.08 & $(0.15)$ & 0.02 & $(0.16)$ & 0.05 & $(0.18)$ & 0.01 & $(0.16)$ \\
\hline $\mathrm{LP}-2 \times \mathrm{DH}$ & -0.06 & $(0.17)$ & -0.04 & $(0.15)$ & -0.06 & $(0.15)$ & -0.05 & $(0.22)$ & -0.07 & $(0.15)$ \\
\hline $\mathrm{LP}-1 \times \mathrm{DH}$ & 0.05 & $(0.13)$ & 0.08 & $(0.13)$ & 0.07 & $(0.13)$ & 0.05 & $(0.11)$ & 0.06 & $(0.14)$ \\
\hline $\mathrm{LP} \times \mathrm{DH}$ & $0.30^{* *}$ & $(0.13)$ & $0.30^{* *}$ & $(0.14)$ & $0.30^{* *}$ & $(0.13)$ & $0.27^{*}$ & $(0.14)$ & $0.30^{* *}$ & $(0.14)$ \\
\hline $\mathrm{LP}+1 \times \mathrm{DH}$ & 0.16 & $(0.14)$ & $0.25^{*}$ & $(0.15)$ & 0.11 & $(0.14)$ & 0.16 & $(0.15)$ & 0.11 & $(0.14)$ \\
\hline $\mathrm{LP}+2 \times \mathrm{DH}$ & 0.16 & $(0.16)$ & $0.27^{*}$ & $(0.16)$ & 0.13 & $(0.16)$ & 0.18 & $(0.16)$ & 0.13 & $(0.16)$ \\
\hline $\mathrm{LP}+3 \times \mathrm{DH}$ & 0.06 & $(0.16)$ & 0.18 & $(0.15)$ & 0.05 & $(0.16)$ & 0.12 & $(0.15)$ & 0.05 & $(0.16)$ \\
\hline $\mathrm{LP}-3 \times \mathrm{CG}$ & 0.01 & $(0.14)$ & 0.12 & $(0.13)$ & 0.05 & $(0.15)$ & 0.31 & $(0.22)$ & 0.02 & $(0.14)$ \\
\hline $\mathrm{LP}-2 \times \mathrm{CG}$ & 0.08 & $(0.14)$ & 0.13 & $(0.13)$ & -0.07 & $(0.11)$ & 0.04 & $(0.28)$ & -0.07 & $(0.11)$ \\
\hline $\mathrm{LP}-1 \times \mathrm{CG}$ & 0.05 & $(0.15)$ & -0.24 & $(0.16)$ & -0.11 & $(0.15)$ & 0.13 & $(0.13)$ & -0.11 & $(0.14)$ \\
\hline $\mathrm{LP} \times \mathrm{CG}$ & 0.04 & $(0.21)$ & -0.14 & $(0.14)$ & -0.03 & $(0.12)$ & 0.07 & $(0.16)$ & -0.02 & $(0.12)$ \\
\hline $\mathrm{LP}+1 \times \mathrm{CG}$ & 0.02 & $(0.17)$ & -0.11 & $(0.14)$ & -0.09 & $(0.14)$ & -0.03 & $(0.17)$ & -0.10 & $(0.13)$ \\
\hline $\mathrm{LP}+2 \times \mathrm{CG}$ & 0.15 & $(0.18)$ & -0.20 & $(0.13)$ & 0.01 & $(0.14)$ & 0.06 & $(0.14)$ & 0.02 & $(0.14)$ \\
\hline $\mathrm{LP}+3 \times \mathrm{CG}$ & -0.01 & $(0.18)$ & -0.10 & $(0.12)$ & -0.14 & $(0.14)$ & -0.09 & $(0.13)$ & -0.16 & $(0.14)$ \\
\hline $\mathrm{DH}$ & $-0.39^{* * *}$ & $(0.07)$ & 0.08 & $(0.10)$ & $0.61^{* * *}$ & $(0.17)$ & $0.32^{* * *}$ & $(0.10)$ & $0.59^{* * *}$ & $(0.17)$ \\
\hline Macro cov. & Yes & & Yes & & Yes & & Yes & & Yes & \\
\hline Financial cov. & Yes & & Yes & & Yes & & Yes & & Yes & \\
\hline F-test & 0.00 & & 0.00 & & 0.00 & & 0.00 & & 0.00 & \\
\hline $\mathrm{R}^{2}$ & 0.68 & & 0.62 & & 0.65 & & 0.64 & & 0.65 & \\
\hline Observations & 2036 & & 2036 & & 2036 & & 2036 & & 2036 & \\
\hline
\end{tabular}

Notes: S.E. clustered at the country-level. All specifications include year and country fixed effects. Inflation equation appears in the online Appendix. The macroeconomic and financial covariates are as in Columns (2)-(5) of Table $2 .{ }^{*} \mathrm{p}<0.10 ;{ }^{* *} \mathrm{p}<0.05 ;{ }^{* * *} \mathrm{p}<0.01$ 
One might be concerned that our results are driven either by the large number of LP introductions in 2004 or by the fact that many MS acquisitions in our data come from three countries: the U.S., Japan, and Spain. We therefore re-estimate Table 2, but now drop from the sample MS acquisitions from the nine countries that introduced a national LP in 2004 (Belgium, Finland, Latvia, Luxembourg, New Zealand, Poland, Romania, South Africa and Switzerland). We then repeat the exercise by dropping from the sample MS acquisitions from the U.S., Japan, and Spain. The results, presented in Tables A5 and A6 in the Appendix, show that our results are not driven by specific years or specific countries: the introduction of an LP still has a significant positive effect on domestic horizontal MS acquisitions in the year in which the LP is introduced but not in other years.

Finally, we ran a placebo test by assigning a random year for the introduction of a national LP for each country in the dataset. We repeat this procedure 1,000 times to get 1,000 randomized LP samples. For each sample, we run specification (2) of our baseline regressions presented in Tables 2-3 and save the relevant coefficients. We then compare the coefficient with those obtained from the true LP introduction. In Figure 4, we report the distribution of the coefficients (left-hand charts) and the p-values (right-hand charts) for our two dependent variables. The vertical red lines represent the actual coefficient of the true sample in the left-hand charts, and the p-value in the right-hand charts.
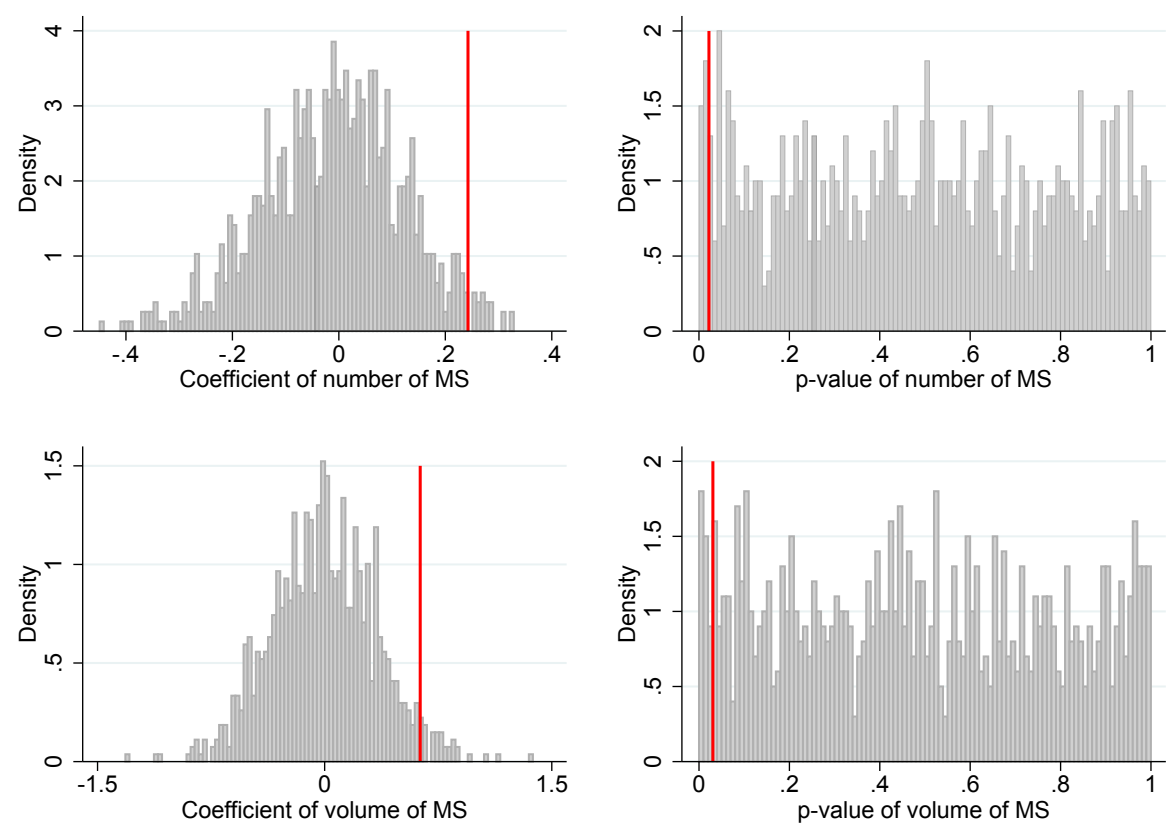

Figure 4: Random samples - Number of new MS and Aggregate volume of new MS 


\section{Conclusion}

Recently, antitrust authorities began paying attention to MS among rival firms. For example, the European Commission started a public consultation in 2013 (European Commission, 2014) on whether acquisition of non-controlling MS should be notified and examined by the Commission. ${ }^{32}$ The concern is that MS acquisitions give rise to unilateral and coordinated anticompetitive effects. There is already some evidence that MS acquisitions may harm competition. The question of course is whether this is due to unilateral or coordinated effects.

In this paper, we study the latter possibility and examine whether MS acquisitions are likely to facilitate collusion. To this end, we exploit the fact that the introduction of an LP is a negative shock that destabilize collusive agreements. Firms may react to this negative shock by acquiring MS in rivals either in order to stabilize their collusive agreements, or to soften competition if collusion is going to break down. Consistent with this idea, we find that the introduction of an LP is followed by a significant increase in the number of MS acquisitions and in their volume. This effect is present however only in countries with an effective antitrust enforcement and low levels of corruption, where the introduction of an LP is indeed likely to destabilize collusive agreements. Moreover, we find that the increase in MS acquisitions is significant when it comes to large rivals (i.e., targets with abovemedian market capitalization) and when the acquisitions involve stakes of $10 \%-20 \%$. As mentioned earlier, typically such stakes do not trigger merger notification, and hence allows colluding firms to stay "under the radar."

As far as we know, our paper is the first to provide evidence for the collusive effect of MS acquisitions. While there is already a theoretical literature that shows that MS acquisitions can facilitate collusion, so far this possibility did not receive an empirical support. Our results suggest that MS acquisitions are potentially anticompetitive, especially when it comes to acquisitions of intermediate levels of MS stakes in large rivals and hence it would be a good idea to incorporate them into the merger control procedures, as is done, to some extent, in some countries like Austria, Germany, or the UK.

\footnotetext{
${ }^{32}$ For further information on the EU Merger Control process, please see http://ec.europa.eu/competition/ mergers/ procedures_en.html (last accessed on 24 June 2017).
} 


\section{References}

[1] Abrantes-Metz, R., J. Connor, and A. Metz (2013), "The Determinants of Cartel Duration," Unpublished Working Paper, New York.

[2] Allen, J. and G. Phillips (2000), "Corporate Equity Ownership, Strategic Alliances, and Product Market Relationships," Journal of Finance, 55, 2791-2815.

[3] Azar, J., M. Schmalz, and I. Tecu (2016), "Anti-Competitive Effects of Common Ownership," Ross School of Business Working Paper No. 1235.

[4] Azar, J., S. Raina, and M. Schmalz (2016), "Ultimate Ownership and Bank Competition," Mimeo.

[5] Brenner, S. (2009), "An Empirical Study on the European Corporate Leniency Program," International Journal of Industrial Organization, 27, 639-645.

[6] Brito, D., Ribeiro, R., and H. Vasconcelos (2014), "Measuring Unilateral Effects in Partial Horizontal Acquisitions," International Journal of Industrial Organization, 33, 22-36.

[7] Brito, D., Cabral L., and H. Vasconcelos (2014), "Divesting ownership in a rival," International Journal of Industrial Organization, 34, 9-24.

[8] Bresnahan T. and S. Salop (1986), "Quantifying the Competitive Effects of Joint Ventures," International Journal of Industrial Organization, Vol. 4, pp. 155-175.

[9] Cameron, A. C., and F. A. G. Windmeijer (1996), "R-squared measures for count data regression models with applications to health-care utilization, "Journal of Business and Economic Statistics, 14(2), 209-220.

[10] Davies, S., P. Ormosi, and M. Graffenberger (2015), "Mergers after Cartels: How Markets React to Cartel Breakdown," Journal of Law and Economics, 58(3), 561-583.

[11] De, O. (2010), "Analysis of Cartel Duration: Evidence from EC Prosecuted Cartels," International Journal of the Economics of Business, 17, 33- 65.

[12] Dick, A. (1996), "When Are Cartels Stable Contracts?" Journal of Law and Economics, 39, 241-283.

[13] Dietzenbacher, E., Smid B., and B. Volkerink (2000), "Horizontal integration in the Dutch financial sector," International Journal of Industrial Organization, Vol. 18, 1223-1242.

[14] Di Giovanni, J. (2005), "What Drives Capital Flows? The Case of Cross-Border M\&A Activity and Financial Deepening," Journal of International Economics, 65(1), 127-149.

[15] Dong, A., M. Massa, and A. Zaldokas (2016), "Busted! Now What? Effects of Cartel Enforcement on Firm Value and Corporate Policies," CEPR Discussion Paper DP11470, London. 
[16] Erel, I., R. Liao, and M. Weisbach (2012), "Determinants of Cross-Border Mergers and Acquisitions," Journal of Finance, 67(3), 1045-1082.

[17] European Commission (2014), Commission Staff Working Document Impact Assessment Accompanying the document White paper "Towards More Effective EU Merger Control," Brussels, 9.7.2014, SWD(2014) 217 final

[18] European Commission (2013), Annex I to the Commission Staff Working Document "Towards More Effective EU Merger Control": Economic Literature on Non-Controlling Minority Shareholdings ("Structural links"), SWD(2013) 239 final, Brussels.

[19] Farrell, J. and C. Shapiro (1990), "Asset Ownership and Market Structure in Oligopoly," RAND Journal of Economics, Vol. 21, 275-292.

[20] Fee, C., C. Hadlock, and S. Thomas (2006), "Corporate Equity Ownership and the Governance of Product Market Relationships," Journal of Finance, 61, 1217-1251.

[21] Feld, L., M. Ruf, U. Schreiber, M. Todtenhaupt and J. Voget (2016), "Taxing Away M\&A: The Effect of Corporate Capital Gains Taxes on Acquisition Activity," ZEW Discussion Paper No. 16-007, Mannheim.

[22] Foros, H-J. Kind, and G. Shaffer (2011), "Mergers and Partial Ownership," European Economic Review, 55(7), 916- 926.

[23] Fotis P. and N. Zevgolis (2016), The Competitive Effects of Minority Shareholdings: Legal and Economic Issues, Hart Publishing.

[24] Gilo, D., (2000), "The Anticompetitive Effect of Passive Investment," Michigan Law Review, Vol. 99 (2000), 1-47.

[25] Gilo, D., Y. Moshe and Y. Spiegel (2006), "Partial Cross Ownership and Tacit Collusion," RAND Journal of Economics, 37, 81-99.

[26] Grossman, Sanford J., and Oliver D. Hart (1980), "Takeover Bids, the Free-Rider Problem, and the Theory of the Corporation," The Bell Journal of Economics, 11(1), 42-64.

[27] Hardin, J. and J. Hilbe (2001), Generalized Linear Models and Extensions, College Station: Stata Press.

[28] Harrington, J. (2013), "Corporate Leniency Programs When Firms Have Private Information: The Push of Prosecution and the Pull of Pre-Emption," Journal of Industrial Economics, 61, $1-27$.

[29] Harrington, J. (2008), "Optimal Corporate Leniency Programs," Journal of Industrial Economics, 56, 215-246. 
[30] Harrington, J. and M.-H. Chang (2009), "Modelling the Birth and Death of Cartels with an Application to Evaluating Antitrust Policy," Journal of the European Economic Association, $7(6), 1400-1435$.

[31] Harrington, J. and M.-H. Chang (2013), "When Should We Expect a Corporate Leniency Program to Result in Fewer Cartels?" Journal of Law and Economics, 58, 417-449.

[32] Hebous, S., M. Ruf, and A. Weichenrieder (2011), "The Effects of Taxation on The Location Decision Of Multinational Firms: M\&A Versus Greenfield Investments," National Tax Journal, 64(3), 817-38.

[33] Hellwig, M. and K. Hüschelrath (2017), "When Do Firms Leave Cartels? Determinants and the Impact on Cartel Survival," ZEW Discussion Paper No. 17-002, Mannheim.

[34] Hellwig, M. and K. Hüschelrath (2016), "Cartel Cases and the Cartel Enforcement Process in the European Union 2001 -2015: A Quantitative Assessment," ZEW Discussion Paper No. 16-063, Mannheim.

[35] Hilbe, J. (2014), Modelling Count Data, Cambridge University Press.

[36] Hoang, C. T., K. Hüschelrath, U. Laitenberger, and F. Smuda (2014), "Determinants of SelfReporting under the European Corporate Leniency Program," International Review of Law and Economics, 40, 15-23.

[37] Jovanovic D. and C. Wey (2014), "Passive Partial Ownership, Sneaky Takeovers, and Merger Control, Economics Letters, 125, 32-35.

[38] Levenstein, M. and V. Suslow (2011), "Breaking Up is Hard to Do: Determinants of Cartel Duration," Journal of Law and Economics, 54, 455-492.

[39] Lopez A. and X. Vives (2016), "Cross-ownership, R\&D Spillovers and Antitrust Policy," Mimeo.

[40] Malueg, D. (1992), "Collusive Behavior and Partial Ownership of Rivals," International Journal of Industrial Organization, 10, 27-34.

[41] Marx, L. and J. Zhou (2015), "The Dynamics of Mergers Among (Ex)Co-Conspirators in the Shadow of Cartel Enforcement," Working Paper, Tilburg.

[42] Meadowcroft, S. and D. Thompson (1986), "Minority Share Acquisitions: The Impact Upon Competition," Commission of the European Communities, Luxembourg.

[43] Motta, M. and M. Polo (2003), "Leniency Programs and Cartel Prosecution," International Journal of Industrial Organization, 21, 347-379.

[44] Miller, N. (2009), "Strategic Leniency and Cartel Enforcement," American Economic Review, 99(3), 750-768. 
[45] Nain, A. and Y. Wang (2016), "The Product Market Impact of Minority Stake Acquisitions," Management Science, Published online in Articles in Advance 16 Nov 2016.

[46] O'Brien, D. and K. Waehrer (2017), "The Competitive Effects of Common Ownership: We Know Less Than We Think," Mimeo.

[47] OECD (2012), "Leniency for Subsequent Applicants," Working Party No. 3 on Co-operation and Enforcement, DAF/COMP/WP3(2012)9, Paris.

[48] OECD (2008), "Antitrust Issues Involving Minority Shareholdings and Interlocking Directorates," DAF/COMP(2008)30, Paris.

[49] Panayides M. and S. Thomas (2017), "Commonality in Institutional Ownership and Competition in Product Markets," Mimeo.

[50] Parker Ouimet, P. (2013), "What Motivates Minority Acquisitions? The Trade-Offs between a Partial Equity Stake and Complete Integration," Review of Financial Studies, 26, 1021-1047.

[51] Reynolds, R. and B. Snapp (1986), "The Competitive Effects of Partial Equity Interests and Joint Ventures," International Journal of Industrial Organization, 4, 141-153.

[52] Rossi, S. and P. Volpin (2004), "Cross-Country Determinants of Mergers and Acquisitions," Journal of Financial Economics, 74(2), 277-304.

[53] Salop, S. and D. O'Brien (2000), "Competitive Effects of Partial Ownership: Financial Interest and Corporate Control," Antitrust Law Journal, 67, 559-614.

[54] Sovinsky, M. and E. Helland (2012), "Do Research Joint Ventures Serve a Collusive Function," Warwick Economic Research Papers No 1030, Coventry.

[55] Shelegia, S. and Y. Spiegel (2012), "Bertrand Competition When Firms Hold Passive Ownership Stakes in One Another," Economics Letters, 114, 136-138.

[56] Shelegia, S. and Y. Spiegel (2016), "Cost-Reducing Investments under Partial CrossOwnership," Mimeo

[57] Spagnolo, G. (2005), "Divide et Impera: Optimal Leniency Programs," CEPR Discussion Paper DP4840, London.

[58] Spagnolo, G. and C. Marvao (2016), "Cartels and Leniency: Taking Stock of What We Learnt," forthcoming in Handbook of Game Theory and Industrial Organization, L. C. Corchón and M. A. Marini (ed.), Edward Elgar, Cheltenam, UK and Northampton, MA

[59] UNCTAD (2010), "The Use of Leniency Programmes as a Tool for the Enforcement of Competition Law Against Hardcore Cartels in Developing Countries," Sixth United Nations Conference to Review All Aspects of the Set of Multilaterally Agreed Equitable Principles and Rules for the Control of Restrictive Business Practices, 8-12 November 2010, Geneva. 
[60] Zheng, B. and A. Agresti (2000), "Summarizing the Predictive Power of a Generalized Linear Model," Statistics in Medicine, 19, 1771-1781.

[61] Zhou, J. (2016), "The Dynamics of Leniency Application and the Knock-on Effect of Cartel Enforcement," Bruegel Working Paper 2016/02, Brussels.

[62] Zhou, J. (2012), "Cartel Duration and Endogenous Private Monitoring and Communication: An Instrumental Variables Approach," Discussion Paper Series of SFB/TR 15 Governance and the Efficiency of Economic Systems No. 369, Mannheim. 


\section{A Appendix}

The following two tables report results from model choice tests suggesting which model should be prefered over another. In particular Poisson and Negative Binomial models as well as their zeroinflated counterparts are compared. In addition to the Akaike and the Bayesian Information Criteria (AIC and BIC, a lower value means a better model fit and should be preferred) we also report the Likelihood-Ratio (LRX2)) for nested models and the the Vuong Test for non-nested models.

Table A1a: Tests and statistics of the model fit for the number of new new domestic horizontal MS acquisitions

\begin{tabular}{|c|c|c|c|c|c|c|c|}
\hline Poisson & & $\mathrm{BIC}=8137$ & $\mathrm{AIC}=$ & 7620 & Prefer & Over & Evidence \\
\hline \multirow[t]{3}{*}{ vs } & NegBin & $\mathrm{BIC}=6437$ & $\operatorname{dif}=$ & 1699 & NegBin & Poisson & Very strong \\
\hline & & $\mathrm{AIC}=5915$ & $\operatorname{dif}=$ & 1705 & NegBin & Poisson & \\
\hline & & LRX2 $=1707$ & prob $=$ & 0 & NegBin & Poisson & $\mathrm{p}=0.00$ \\
\hline \multirow[t]{3}{*}{ vs } & ZIP & $\mathrm{BIC}=8023$ & $\operatorname{dif}=$ & 114 & ZIP & Poisson & Very strong \\
\hline & & $\mathrm{AIC}=7480$ & $\operatorname{dif}=$ & 140 & ZIP & Poisson & \\
\hline & & Vuong $=3.00$ & prob $=$ & 0 & ZIP & Poisson & $\mathrm{p}=0.00$ \\
\hline \multirow[t]{2}{*}{ vs } & ZINB & $\mathrm{BIC}=6455$ & $\operatorname{dif}=$ & 1682 & ZINB & Poisson & Very strong \\
\hline & & $\mathrm{AIC}=5907$ & $\operatorname{dif}=$ & 1713 & ZINB & Poisson & \\
\hline NegBin & & $\mathrm{BIC}=6437$ & $\mathrm{AIC}=$ & 5915 & Prefer & Over & Evidence \\
\hline \multirow[t]{2}{*}{ vs } & ZIP & $\mathrm{BIC}=8023$ & $\operatorname{dif}=$ & 1585 & NegBin & ZIP & Very strong \\
\hline & & $\mathrm{AIC}=7480$ & $\operatorname{dif}=$ & 1565 & NegBin & ZIP & \\
\hline \multirow[t]{3}{*}{ vs } & ZINB & $\mathrm{BIC}=6455$ & $\operatorname{dif}=$ & -18 & NegBin & ZINB & Very strong \\
\hline & & $\mathrm{AIC}=5907$ & $\operatorname{dif}=$ & 8 & ZINB & NegBin & \\
\hline & & Vuong $=1.63$ & prob $=$ & 0.05 & ZINB & NegBin & $\mathrm{p}=0.05$ \\
\hline ZIP & & $\mathrm{BIC}=8023$ & $\mathrm{AIC}=$ & 7480 & Prefer & Over & Evidence \\
\hline \multirow[t]{3}{*}{ vs } & ZINB & $\mathrm{BIC}=6455$ & $\operatorname{dif}=$ & 1568 & ZINB & ZIP & Very strong \\
\hline & & $\mathrm{AIC}=5907$ & $\operatorname{dif}=$ & 1573 & ZINB & ZIP & \\
\hline & & $\mathrm{LRX} 2=1575$ & prob $=$ & 0 & ZINB & ZIP & $\mathrm{p}=0.00$ \\
\hline
\end{tabular}

Notes: AIC and BIC present test statistics from Akaike and Bayesian information criteria, LRX2 presents the results from boundary likelihood-ratio tests and Vuong represents the results from Vuong tests. NegBin, ZIP and ZINB abbreviate negative binomial, the zero-inflated Poisson and the zero-inflated negative binomial models. The program Countfit by Long and Freese (2014) is applied for the computation of tests and fit statistics. 
Table A1b: Test and statistics of the model fit for the aggregate volume of new domestic horizontal MS acqusitions

\begin{tabular}{|c|c|c|c|c|c|c|}
\hline Poisson & & $\mathrm{BIC}=160750$ & $\mathrm{AIC}=160233$ & Prefer & Over & Evidence \\
\hline \multirow[t]{3}{*}{ vs } & NegBin & $\mathrm{BIC}=10633$ & $\operatorname{dif}=150117$ & NegBin & Poisson & Very strong \\
\hline & & $\mathrm{AIC}=10111$ & $\operatorname{dif}=150122$ & NegBin & Poisson & \\
\hline & & $\mathrm{LRX} 2=1.50 \mathrm{e}+05$ & prob $=0.00$ & NegBin & Poisson & $\mathrm{p}=0.00$ \\
\hline \multirow[t]{3}{*}{ vs } & ZIP & $\mathrm{BIC}=127051$ & $\operatorname{dif}=33699$ & ZIP & Poisson & Very strong \\
\hline & & $\mathrm{AIC}=126508$ & $\operatorname{dif}=33725$ & ZIP & Poisson & \\
\hline & & Vuong $=11.17$ & prob $=0.00$ & ZIP & Poisson & $\mathrm{p}=0.00$ \\
\hline \multirow[t]{2}{*}{ vs } & ZINB & $\mathrm{BIC}=10528$ & $\operatorname{dif}=150221$ & ZINB & Poisson & Very strong \\
\hline & & $\mathrm{AIC}=9980$ & $\operatorname{dif}=150253$ & ZINB & Poisson & \\
\hline NegBin & & $\mathrm{BIC}=10633$ & $\mathrm{AIC}=10111$ & Prefer & Over & Evidence \\
\hline \multirow[t]{2}{*}{ vs } & ZIP & $\mathrm{BIC}=127051$ & $\operatorname{dif}=-1.164 \mathrm{e}+05$ & NegBin & ZIP & Very strong \\
\hline & & $\mathrm{AIC}=126508$ & $\operatorname{dif}=-1.164 \mathrm{e}+05$ & NegBin & ZIP & \\
\hline \multirow[t]{3}{*}{ vs } & ZINB & $\mathrm{BIC}=10528$ & $\operatorname{dif}=105$ & ZINB & NegBin & Very strong \\
\hline & & $\mathrm{AIC}=9980$ & $\operatorname{dif}=131$ & ZINB & NegBin & \\
\hline & & Vuong $=8.18$ & prob $=0.00$ & ZINB & NegBin & $\mathrm{p}=0.00$ \\
\hline ZIP & & $\mathrm{BIC}=127051$ & $\mathrm{AIC}=126508$ & Prefer & Over & Evidence \\
\hline \multirow[t]{3}{*}{ vs } & ZINB & $\mathrm{BIC}=10528$ & $\operatorname{dif}=116522$ & ZINB & ZIP & Very strong \\
\hline & & $\mathrm{AIC}=9979$ & $\operatorname{dif}=116528$ & ZINB & ZIP & \\
\hline & & $\mathrm{LRX} 2=1.17 \mathrm{e}+05$ & prob $=0.00$ & ZINB & ZIP & $\mathrm{p}=0.00$ \\
\hline
\end{tabular}

Notes: AIC and BIC present test statistics from Akaike and Bayesian information criteria, LRX2 presents the results from boundary likelihood-ratio tests and Vuong represents the results from Vuong tests. NegBin, ZIP and ZINB abbreviate negative binomial, the zero-inflated Poisson and the zero-inflated negative binomial models. The program countfit by Long and Freese (2014) is applied for the computation of tests and fit statistics. 


\section{Data construction}

The following table shows how we constructed the data set that we use in the paper and the number of observations that remained after each step.

Table A2: Construction of the data set on new domestic horizontal MS acquisitions

\begin{tabular}{ccc}
\hline Step & Action & \# remaining observations \\
\hline 1 & All acquisitions in 63 countries during the period 1990-2013, & \\
& where the final stake remains below 50\% & 131,188 \\
2 & Eliminate all acquisitions for which the final stake is not known & 86,432 \\
3 & Eliminate share buybacks and self-tenders & 78,897 \\
4 & Eliminate acquisitions where the acquirer is an investor & 49,495 \\
5 & Eliminate acquisitions where the target is an investor & 47,908 \\
6 & Eliminate cross-border acquisitions & 32,864 \\
7 & Eliminate non-horizontal acquisitions & 13,871 \\
8 & Eliminate increases of already existing MS & 11,504 \\
\hline
\end{tabular}

\section{Cross country data}

This subscetion contains data about the number and deal volume of MS acquisitions and also information regarding the year in which an LP was introduced in each country and statistics about the efficacy of antitrust enforcement and the level of corruption. We begin with the following figures that show the distribution of the number of MS acquisitions and their aggregate deal volume by country for the period 1990-2013.

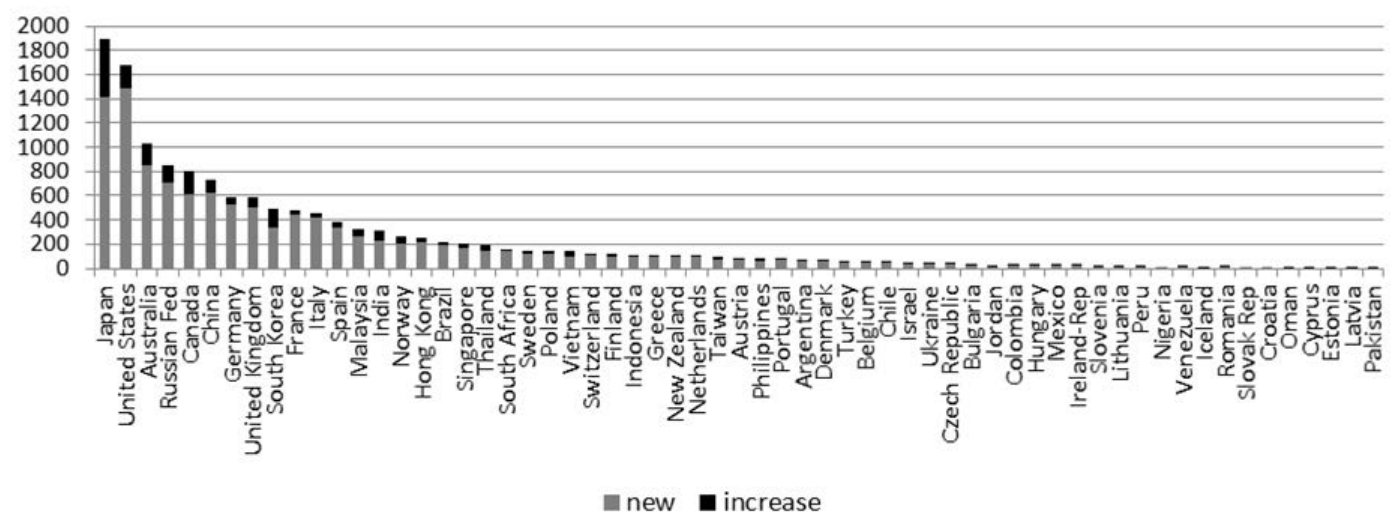

Figure A1: Number of MS acquisitions, new acquisitions and stake increases 


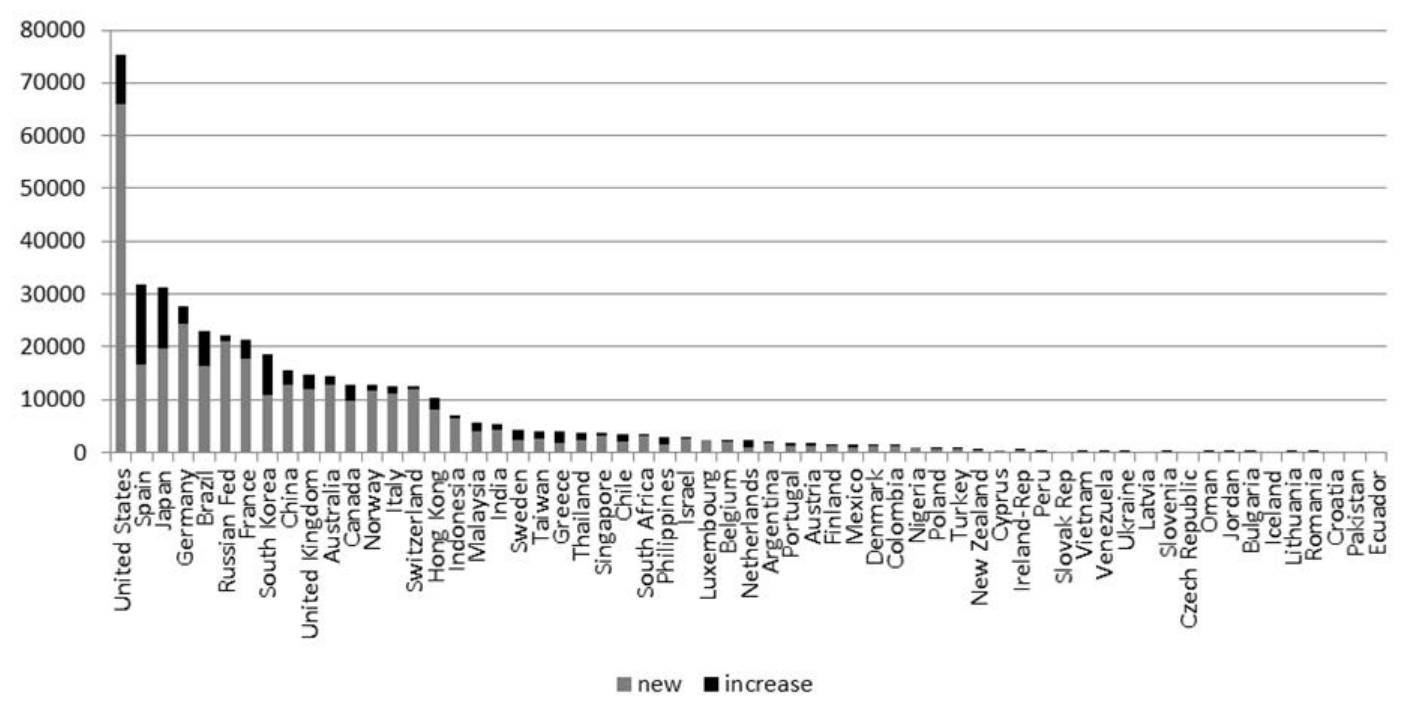

Figure A2: Volume of MS acquisitions, in million USD, new acquisitions and share increases

The next table shows for each country when an LP was introduced (before 2013), if at all. This information is largely taken from Dong et al. (2016). In addition, the table also shows for each country the Anti-Monopoly Policy Index (AMPI) score provided by the World Economic Forum (WEF) and published annually in the Global Competition Review (GCR), and the Corruption Perception Index (CPI) score computed by Transparency International (TI). As mentioned earlier, the AMPI score is on a 1-7 scale, with 7 being the most effective enforcement. The CPI score is on a 1-10 scale, with 10 being the lowest level of corruption. 
Table A3: Country-specific information on leniency programs and enforcement

\begin{tabular}{|c|c|c|c|c|c|c|c|}
\hline Country & Leniency & AMPI & CPI & Country & Leniency & AMPI & CPI \\
\hline Argentina & No LP & 3.2 & . & Luxembourg & 2004 & 5.1 & 8.5 \\
\hline Australia & 2003 & 5.3 & 8.6 & Malaysia & 2010 & $4 . .7$ & 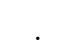 \\
\hline Austria & 2006 & 5.2 & 7.8 & Mexico & 2006 & 3.5 & 3.4 \\
\hline Belgium & 2004 & 5.2 & 6.9 & Netherlands & 2002 & 5.8 & 8.8 \\
\hline Brazil & 2000 & 4.5 & 3.7 & New Zealand & 2004 & 5.5 & 9.4 \\
\hline Bulgaria & 2003 & 3.3 & 3.8 & Nigeria & No LP & 3.9 & . \\
\hline Canada & 2000 & 5.1 & 8.8 & Norway & 2005 & 5.4 & 8.7 \\
\hline Chile & 2009 & 4.9 & & Oman & No LP & 4.4 & \\
\hline China & 2008 & 4.1 & 3.3 & Pakistan & 2007 & 3.9 & \\
\hline Colombia & 2009 & 4.0 & . & Peru & 2005 & 4.0 & . \\
\hline Croatia & 2010 & 3.7 & 3.9 & Philippines & 2009 & 3.7 & \\
\hline Cyprus & 2011 & 4.7 & 6.1 & Poland & 2004 & 4.2 & 4.6 \\
\hline Czech Republic & 2001 & 4.5 & 4.6 & Portugal & 2006 & 4.5 & 6.3 \\
\hline Denmark & 2007 & 5.4 & 9.5 & Romania & 2004 & 3.7 & 3.4 \\
\hline Ecuador & 2011 & 3.0 & . & Russian Fed & 2007 & 3.3 & 2.4 \\
\hline Estonia & 2002 & 4.6 & 6.2 & Singapore & 2006 & 5.3 & . \\
\hline Finland & 2004 & 5.7 & 9.4 & Slovak Rep & 2001 & 4.2 & 4.2 \\
\hline France & 2001 & 5.3 & 6.9 & Slovenia & 2010 & 4.2 & 6.1 \\
\hline Germany & 2000 & 5.5 & 7.9 & South Africa & 2004 & 5.3 & . \\
\hline Greece & 2006 & 4.0 & 4.3 & South Korea & 1997 & 4.7 & 4.8 \\
\hline Hong Kong & No LP & 4.2 & . & Spain & 2008 & 4.5 & 6.3 \\
\hline Hungary & 2003 & 4.1 & 5.0 & Sweden & 2002 & 5.7 & 9.2 \\
\hline Iceland & 2005 & 4.8 & 9.0 & Switzerland & 2004 & 5.1 & 8.8 \\
\hline India & 2009 & 4.7 & 3.0 & Taiwan & 2012 & 5.0 & \\
\hline Indonesia & No LP & 4.6 & . & Thailand & No LP & 4.1 & . \\
\hline Ireland-Rep & 2001 & 5.0 & 7.7 & Turkey & 2009 & 4.6 & 3.9 \\
\hline Israel & 2005 & 4.5 & & Ukraine & 2012 & 3.1 & . \\
\hline Italy & 2007 & 3.8 & 4.6 & United Kingdom & 1998 & 5.4 & 8.3 \\
\hline Japan & 2005 & 5.3 & 7.1 & United States & 1993 & 5.3 & 7.5 \\
\hline Jordan & No LP & 4.4 & . & Venezuela & No LP & 2.8 & . \\
\hline Latvia & 2004 & 4.0 & 4.1 & Vietnam & No LP & . & \\
\hline Lithuania & 2008 & 3.8 & 4.8 & & & & \\
\hline
\end{tabular}




\section{Additional tables}

Table A6 shows ZINB estimations for the aggregate stake of new domestic MS acquisitions. Tables A9-A10 are the counterparts of Tables 2 and 3 in the text, but in Table A9 we omit countries that introduced an LP in 2004, and in Table A10 we omit countries with the largest MS activity. 
Table A4: ZINB estimations of the aggregate stake size of new domestic horizontal MS acquisitions

\begin{tabular}{|c|c|c|c|c|c|}
\hline & $(1)$ & $(2)$ & (3) & $(4)$ & $(5)$ \\
\hline \multirow[t]{2}{*}{ LP-3 } & 0.08 & 0.11 & & & \\
\hline & $(0.12)$ & $(0.13)$ & & & \\
\hline \multirow[t]{2}{*}{ LP-2 } & -0.04 & -0.03 & & & \\
\hline & $(0.10)$ & $(0.11)$ & & & \\
\hline \multirow[t]{2}{*}{ LP-1 } & 0.03 & 0.01 & & & \\
\hline & $(0.10)$ & $(0.11)$ & & & \\
\hline \multirow[t]{2}{*}{ LP } & $0.19^{*}$ & 0.16 & & & 0.12 \\
\hline & $(0.11)$ & $(0.13)$ & & & $(0.13)$ \\
\hline \multirow[t]{2}{*}{$\mathrm{LP}+1$} & 0.04 & 0.07 & & & \\
\hline & $(0.10)$ & $(0.11)$ & & & \\
\hline \multirow[t]{2}{*}{$\mathrm{LP}+2$} & 0.12 & 0.10 & & & \\
\hline & $(0.11)$ & $(0.13)$ & & & \\
\hline \multirow[t]{2}{*}{$\mathrm{LP}+3$} & -0.05 & -0.02 & & & \\
\hline & $(0.12)$ & $(0.14)$ & & & \\
\hline \multirow[t]{2}{*}{ LP x Effective Enforcement } & & & $0.28^{* *}$ & & \\
\hline & & & $(0.13)$ & & \\
\hline \multirow[t]{2}{*}{ LP x Ineffective Enforcement } & & & -0.07 & & \\
\hline & & & $(0.21)$ & & \\
\hline \multirow[t]{2}{*}{ LP x Low Corruption } & & & & $0.35^{* *}$ & \\
\hline & & & & $(0.18)$ & \\
\hline \multirow[t]{2}{*}{ LP x High Corruption } & & & & -0.01 & \\
\hline & & & & $(0.30)$ & \\
\hline \multirow[t]{2}{*}{ After LP } & & & & & -0.04 \\
\hline & & & & & $(0.13)$ \\
\hline Macroeconomic covariates & Yes & Yes & Yes & Yes & Yes \\
\hline Financial covariates & No & Yes & Yes & Yes & Yes \\
\hline F-test on joint significance of covariates & 0.00 & 0.00 & 0.00 & 0.00 & 0.00 \\
\hline $\mathrm{R}^{2}$ & 0.54 & 0.55 & 0.55 & 0.55 & 0.55 \\
\hline Observations & 1368 & 1018 & 1008 & 652 & 1018 \\
\hline
\end{tabular}

Notes: S.E. clustered at the country-level. Inflation equation is reported in the online Appendix. All specifications include year and country fixed effects. The macroeconomc and financial covariates are as in Table 2. ${ }^{*} \mathrm{p}<0.10 ;{ }^{* *} \mathrm{p}<0.05 ;{ }^{* * *} \mathrm{p}<0.01$ 
Table A5: ZINB estimations of the number of new domestic horizontal MS acquisitions (countries dropped if an LP was introduced in 2004)

\begin{tabular}{|c|c|c|c|c|c|}
\hline & (1) & $(2)$ & (3) & (4) & $(5)$ \\
\hline \multirow[t]{2}{*}{$\mathrm{LP}-3$} & 0.01 & 0.03 & & & \\
\hline & $(0.14)$ & $(0.14)$ & & & \\
\hline \multirow[t]{2}{*}{ LP-2 } & -0.01 & -0.01 & & & \\
\hline & $(0.12)$ & $(0.13)$ & & & \\
\hline \multirow[t]{2}{*}{ LP-1 } & 0.05 & 0.03 & & & \\
\hline & $(0.13)$ & $(0.13)$ & & & \\
\hline \multirow[t]{2}{*}{ LP } & $0.19^{*}$ & $0.22^{*}$ & & & 0.18 \\
\hline & $(0.11)$ & $(0.13)$ & & & $(0.14)$ \\
\hline \multirow[t]{2}{*}{$\mathrm{LP}+1$} & 0.12 & 0.15 & & & \\
\hline & $(0.13)$ & $(0.14)$ & & & \\
\hline \multirow[t]{2}{*}{$\mathrm{LP}+2$} & 0.10 & 0.09 & & & \\
\hline & $(0.15)$ & $(0.16)$ & & & \\
\hline \multirow[t]{2}{*}{$\mathrm{LP}+3$} & -0.02 & -0.05 & & & \\
\hline & $(0.13)$ & $(0.14)$ & & & \\
\hline \multirow[t]{2}{*}{ LP x Effective Enforcement } & & & $0.28^{* *}$ & & \\
\hline & & & $(0.14)$ & & \\
\hline \multirow[t]{2}{*}{ LP x Ineffective Enforcement } & & & 0.01 & & \\
\hline & & & $(0.19)$ & & \\
\hline \multirow[t]{2}{*}{ LP x Low Corruption } & & & & $0.33^{*}$ & \\
\hline & & & & $(0.20)$ & \\
\hline \multirow[t]{2}{*}{ LP x High Corruption } & & & & -0.27 & \\
\hline & & & & $(0.42)$ & \\
\hline \multirow[t]{2}{*}{ After LP } & & & & & -0.02 \\
\hline & & & & & $(0.17)$ \\
\hline Year FE & Yes & Yes & Yes & Yes & Yes \\
\hline Country FE & Yes & Yes & Yes & Yes & Yes \\
\hline Macroeconomic covariates & Yes & Yes & Yes & Yes & Yes \\
\hline Financial covariates & No & Yes & Yes & Yes & Yes \\
\hline F-test & 0.00 & 0.00 & 0.00 & 0.00 & 0.00 \\
\hline $\mathrm{R}^{2}$ & 0.67 & 0.65 & 0.66 & 0.62 & 0.66 \\
\hline Observations & 1164 & 875 & 865 & 532 & 875 \\
\hline
\end{tabular}

Notes: S.E. clustered at the country-level. Inflation equation is reported in the online Appendix. All specifications include year and country fixed effects. The macroeconomc and financial covariates are as in Table 2. ${ }^{*} \mathrm{p}<0.10 ;{ }^{* *} \mathrm{p}<0.05 ;{ }^{* * *} \mathrm{p}<0.01$ 
Table A6: ZINB estimations of the number of new domestic horizontal MS acquisitions (countries with the largest MS activity are dropped)

\begin{tabular}{|c|c|c|c|c|c|}
\hline & (1) & $(2)$ & $(3)$ & $(4)$ & $(5)$ \\
\hline \multirow[t]{2}{*}{ LP-3 } & -0.06 & -0.05 & & & \\
\hline & $(0.15)$ & $(0.14)$ & & & \\
\hline \multirow[t]{2}{*}{ LP-2 } & -0.13 & -0.07 & & & \\
\hline & $(0.13)$ & $(0.13)$ & & & \\
\hline \multirow[t]{2}{*}{ LP-1 } & -0.01 & 0.02 & & & \\
\hline & $(0.13)$ & $(0.12)$ & & & \\
\hline \multirow[t]{2}{*}{ LP } & $0.19^{*}$ & $0.22^{*}$ & & & 0.15 \\
\hline & $(0.10)$ & $(0.12)$ & & & $(0.14)$ \\
\hline \multirow[t]{2}{*}{$\mathrm{LP}+1$} & -0.06 & -0.05 & & & \\
\hline & $(0.10)$ & $(0.11)$ & & & \\
\hline \multirow{2}{*}{$\mathrm{LP}+2$} & -0.01 & -0.03 & & & \\
\hline & $(0.12)$ & $(0.14)$ & & & \\
\hline \multirow{2}{*}{$\mathrm{LP}+3$} & -0.08 & -0.06 & & & \\
\hline & $(0.12)$ & $(0.13)$ & & & \\
\hline \multirow[t]{2}{*}{ LP x Effective Enforcement } & & & $0.36^{* * *}$ & & \\
\hline & & & $(0.13)$ & & \\
\hline \multirow[t]{2}{*}{ LP x Ineffective Enforcement } & & & 0.02 & & \\
\hline & & & $(0.18)$ & & \\
\hline \multirow[t]{2}{*}{ LP x Low Corruption } & & & & $0.40^{* * *}$ & \\
\hline & & & & $(0.16)$ & \\
\hline \multirow[t]{2}{*}{ LP x High Corruption } & & & & -0.27 & \\
\hline & & & & $(0.25)$ & \\
\hline \multirow[t]{2}{*}{ After LP } & & & & & -0.18 \\
\hline & & & & & $(0.15)$ \\
\hline Macroeconomic covariates & Yes & Yes & Yes & Yes & Yes \\
\hline Financial covariates & No & Yes & Yes & Yes & Yes \\
\hline F-test & 0.00 & 0.00 & 0.00 & 0.00 & 0.00 \\
\hline $\mathrm{R}^{2}$ & 0.66 & 0.66 & 0.67 & 0.66 & 0.66 \\
\hline Observations & 1296 & 958 & 948 & 592 & 958 \\
\hline
\end{tabular}

Notes: S.E. clustered at the country-level. Inflation equation is reported in the online Appendix. All specifications include year and country fixed effects. The macroeconomc and financial covariates are as in Table 2. ${ }^{*} \mathrm{p}<0.10 ;{ }^{* *} \mathrm{p}<0.05 ;{ }^{* * *} \mathrm{p}<0.01$ 